ANL-ARC-227

\title{
Feasibility Study on AFR-100 Fuel Conversion from Uranium-based Fuel to Thorium-based Fuel
}

by

F. Heidet, T. K. Kim and C. Grandy

Nuclear Engineering Division, Argonne National Laboratory

June 30, 2012 
(Blank intentionally) 


\section{Executive summary}

The feasibility study of converting a fast reactor from uranium-based fuel to thorium-based fuel was studied using the $100 \mathrm{MW}$ Advanced Fast Reactor (AFR-100). Several fuel conversion scenarios were envisioned in this study.

The first approach is a progressive fuel conversion without fissile support. It consists of progressively replacing the burnt uranium-based fuel with pure thorium-based fuel without fissile material addition. This was found to be impractical because the low excess reactivity of the uranium-fueled AFR-100 core, resulting in an extremely short cycle length even when only a few assemblies are replaced.

A second approach consists in operating the reference LEU fueled AFR-100 core for 24 years and then replacing one fuel batch out of four every 7.04 years with thoriumbased fuel with TRU fissile support. The TRU weight fraction required during the transition period is identical to that required at equilibrium and is equal to $18.6 \%$. The original LEU fuel is discharged with an average burnup of $120 \mathrm{GWd} / \mathrm{t}$ and the Th-TRU fuel with an average burnup of $101 \mathrm{GWd}$ t. The thermal-hydraulic and passive safety performances of this core are similar to those of the reference AFR-100 design. However, Th-TRU fuel fabrication and performance needs to be demonstrated and TRU separation from the LWR used nuclear fuel is necessary.

The third approach proposed consists of replacing the whole AFR-100 core with fuel assemblies made of several thorium and LEU layers. The mode of operation is similar to that of the reference AFR-100 core with the exception of the cycle length that needs to be reduced from 30 to 18 years. The average LEU and thorium discharge burnups are $79 \mathrm{GWd} / \mathrm{t}$ and $23 \mathrm{GWd} / \mathrm{t}$, respectively. The major benefit of this approach is the significantly smaller coolant void worth than for the other scenarios, improving the inherent safety characteristics of the reactor. In addition, no TRU or fissile material needs to be mixed with thorium. 


\section{Table of Contents}

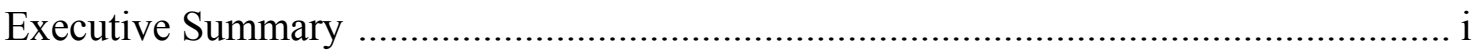

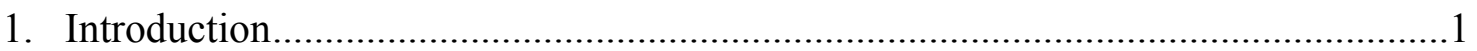

2. Design Bases, Computation Methods and Core Concept ………..............................

2.1 Comparison of Uranium and Thorium based Fuels ........................................... 3

2.2 Design Objectives and Requirements ………….........................................

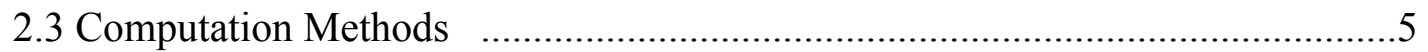

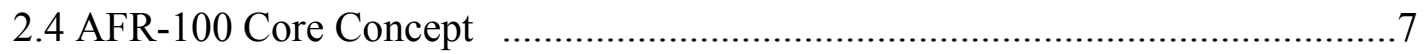

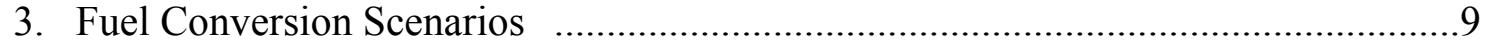

3.1 Progressive Fuel Conversion Scenario without Fissile Support ……………...10

3.2 Progressive Fuel Conversion Scenario with Fissile Support ……………….....13

3.3 Whole Core Fuel Conversion Scenario with Fissile Support ………………....18

4. Orifice Design and Steady-State Thermal-Hydraulic Performance ..........................23

4.1 Th-TRU Fueled Core based on Progressive Fuel Conversion Scenario ...........23

4.2 LEU/Th Fueled Core based on Whole Core Fuel Conversion Scenario ..........26

5. Kinetics Parameters and Reactivity Feedback Coefficients ......................................30

5.1 Th-TRU Fueled Core based on Progressive Fuel Conversion Scenario ............30

5.2 LEU/Th Fueled Core based on Whole Core Fuel Conversion Scenario ...........33

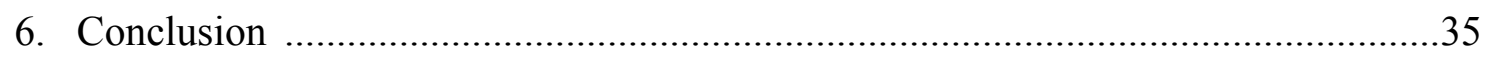

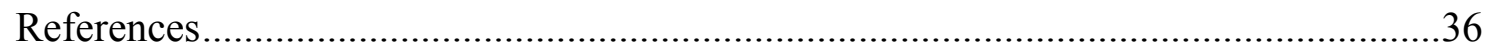

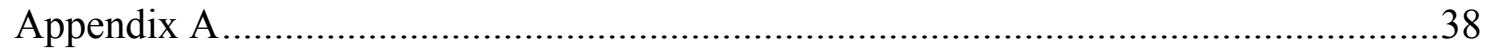

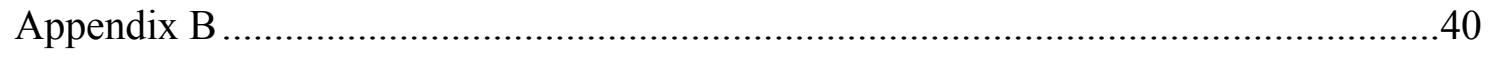




\section{Tables}

Table 2.1 Comparison of Uranium and Thorium Properties ...................................... 3

Table 3.1 Transuranics Vector............................................................................ 9

Table 3.2 Core Performance Parameters for the Th-TRU Fueled AFR-100 ............. 15

Table 3.3 Heavy Metal Mass Flow for the Transition Period of the Th-TRU fueled

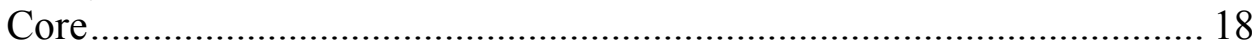

Table 3.4 Heavy Metal Mass Flow at Equilibrium for the Th-TRU Fueled Core..... 18

Table 3.5 Core Performance Parameters of the LEU/Th fueled AFR-100 Core....... 20

Table 3.6 Heavy Metal Mass Flow for the LEU/Th fueled AFR-100 Core .............. 22

Table 5.1 Kinetics Parameters and Reactivity Feedback Coefficient for the Th-TRU

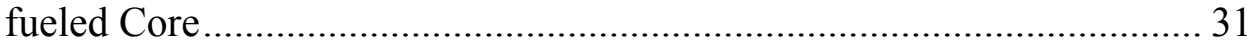

Table 5.2 Integral Reactivity Parameters for Quasi-Static Reactivity Balance for the Th-TRU Fueled Core ………………….................................................. 33

Table 5.3 Kinetics Parameters and Reactivity Feedback Coefficient for the LEU/Th Fueled Core

Table 5.4 Integral Reactivity Parameters for Quasi-Static Reactivity Balance for the LEU/Th fueled AFR-100 Core .............................................................. 34

Table A.1 Basic Core Characteristics at Equilibrium................................................. 39 


\section{Figures}

Figure $2.1 \eta$ Evolution for some Major Actinides .................................................. 4

Figure 2.2 Radial Core Layout of AFR-100 Core .............................................. 8

Figure 2.3 Relative Uranium Enrichment Distribution in the Reference AFR-100

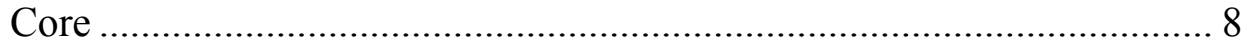

Figure $3.1 \mathrm{k}_{\mathrm{eff}}$ Evolution for the Fuel Replacement Occurring in the Inner Core Region ................................................................................. 11

Figure $3.2 \mathrm{k}_{\mathrm{eff}}$ Evolution for the Fuel Replacement Occurring in the Middle Core

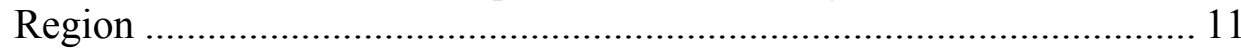

Figure $3.3 \mathrm{k}_{\mathrm{eff}}$ Evolution for the Fuel Replacement Occurring in the Outer Core Region

Figure $3.4 \mathrm{k}_{\mathrm{eff}}$ Evolution for Various Number of Assemblies Replaced in the Outer Core Region................................................................................... 13

Figure 3.5 Th-TRU Fueled AFR-100 Core Layout for a 4-batches Strategy ............ 14

Figure $3.6 \mathrm{k}_{\mathrm{eff}}$ Evolution of the Th-TRU Fueled AFR-100 Core during Transition and at Equilibrium for a 4-batches Strategy.

Figure 3.7 Radial Power Distribution ( $\mathrm{MW}_{\text {th }}$ per Assembly) in 1/3 of the Th-TRU Fueled Core during Transition

Figure 3.8 Radial Power Distribution ( $\mathrm{MW}_{\text {th }}$ per Assembly) in 1/3 of the Th-TRU Fueled Core at Equilibrium

Figure 3.9 Inner, Middle and Outer Fuel Assemblies Layers (in cm) 19

Figure $3.10 \mathrm{k}_{\mathrm{eff}}$ Evolution of the LEU/Th Fueled AFR-100 Core... 20

Figure 3.11 Radial Power Distribution ( $\mathrm{MW}_{\text {th }}$ per Assembly) in 1/3 of the LEU/Th Fueled Core at BOL and EOL ........................................................ 21

Figure 4.1 Orifice Zones for the Th-TRU Fueled Core.......................................... 24

Figure 4.2 Coolant Flow Rate and Velocity for the Th-TRU Fueled Core ............... 24

Figure 4.3 Peak $2 \sigma$ Cladding Inner Wall Temperatures $\left({ }^{\circ} \mathrm{C}\right)$ for the Th-TRU Fueled Core

Figure 4.4 Mixed Mean Coolant Output Temperatures $\left({ }^{\circ} \mathrm{C}\right)$ for the Th-TRU Fueled Core 26

Figure 4.5 Orifice Zones for the LEU/Th Fueled Core 27

Figure 4.6 Coolant Flow Rate and Velocity for the LEU/Th Fueled Core. 27

Figure 4.7 Peak $2 \sigma$ Cladding Inner Wall Temperatures $\left({ }^{\circ} \mathrm{C}\right)$ for the LEU/Th Fueled Core 28 
Figure 4.8 Mixed Mean Coolant Output Temperatures $\left({ }^{\circ} \mathrm{C}\right)$ for the LEU/Th Fueled

Core

Figure 5.1 Sodium Void Worth and Doppler Coefficient Evolution for the Th-TRU

Fueled Core

Figure 5.2 Axial and Radial Expansion Coefficients Evolution for the Th-TRU Fueled Core 32

Figure A.1 $\mathrm{k}_{\mathrm{eff}}$ Evolution for Different Number of Batches with TRU Support .........38

Figure B.1 keff Relative Radial Power Distribution for Layout A ................................40

Figure B.2 $\mathrm{k}_{\text {eff }}$ Relative Radial Power Distribution for Layout B ...............................41

Figure B. $3 \mathrm{k}_{\text {eff }}$ Relative Radial Power Distribution for Layout C ...............................41

Figure B.4 keff Relative Radial Power Distribution for Layout D ...............................42

Figure B.5 Figure B. $5 \mathrm{k}_{\text {eff }}$ Evolution for the Four Core Layouts.................................42 


\section{Introduction}

Although thorium has long been considered as an alternative to uranium-based fuels, most of the reactors built to-date have been fueled with uranium-based fuel with the exception of a few reactors. The decision to use uranium-based fuels was initially made based on the technology maturity compared to thorium-based fuels. As a result of this experience, lot of knowledge and data have been accumulated for uranium-based fuels that made it the predominant nuclear fuel type for extant nuclear power. However, following the recent concerns about the extent and availability of uranium resources, thorium-based fuels have regained significant interest worldwide. Thorium is more abundant than uranium and can be readily exploited in many countries and thus is now seen as a possible alternative. As thorium-based fuel technologies mature, fuel conversion from uranium to thorium is expected to become a major interest in both thermal and fast reactors.

In this study the feasibility of fuel conversion in a fast reactor is assessed and several possible approaches are proposed. The analyses are performed using the Advanced Fast Reactor (AFR-100) design [1], a fast reactor core concept recently developed by ANL. The AFR-100 is a small $100 \mathrm{MW}_{\mathrm{e}}$ reactor developed under the US-DOE program relying on innovative fast reactor technologies and advanced structural and cladding materials. It was designed to be inherently safe and offers sufficient margins with respect to the fuel melting temperature and the fuel-cladding eutectic temperature when using U-10Zr binary metal fuel.

Thorium-based metal fuel was preferred to other thorium fuel forms because of its higher heavy metal density and it does not need to be alloyed with zirconium to reduce its radiation swelling. The various approaches explored cover the use of pure thorium fuel as well as the use of thorium mixed with transuranics (TRU). Sensitivity studies were performed for the different scenarios envisioned in order to determine the best core performance characteristics for each of them. With the exception of the fuel type and enrichment, the reference AFR-100 core design characteristics were kept unchanged, including the general core layout and dimensions, assembly dimensions, materials and power rating. In addition, the mass of ${ }^{235} \mathrm{U}$ required was kept within a reasonable range from that of the reference AFR-100 design.

The core performance characteristics, kinetics parameters and reactivity feedback coefficients were calculated using the ANL suite of fast reactor analysis code systems [28]. Orifice design calculations and the steady-state thermal-hydraulic analyses were performed using the SE2-ANL code [9]. The thermal margins were evaluated by comparing the peak temperatures to the design limits for parameters such as the fuel melting temperature and the fuel-cladding eutectic temperature. The inherent safety features of AFR-100 cores proposed were assessed using the integral reactivity parameters of the quasi-static reactivity balance analysis [10].

The design objectives and requirements, the computation methods used as well as a description of the core concept are provided in Section 2. The three major approaches considered are introduced in Section 3 and the neutronics performances of those approaches are discussed in the same section. The orifice zoning strategies used and the steady-state thermal-hydraulic performance are provided in Section 4. The kinetics and 
reactivity coefficients, including the inherent safety characteristics, are provided in Section 5, and the Conclusions in Section 6. Other scenarios studied and sensitivity studies are provided in the Appendix section. 


\section{Design Bases, Computation Methods and Core Concept}

\subsection{Comparison of Uranium and Thorium based Fuels}

When used in a thermal reactor thorium is typically a better fertile material than uranium, but in fast reactors use of thorium fuel in place of uranium fuel may impair the reactor performance. The primary properties of uranium and thorium are compared in Table 2.1 and the number of neutrons yielded per neutron absorption $(\eta)$ is shown in Figure 2.1 for the major fissile nuclides. Since natural thorium does not contain any fissile isotope, it is necessary to support thorium-based fuel with fissile material such as low enriched uranium (LEU), plutonium or transuranics (TRU), until enough ${ }^{233} \mathrm{U}$ is bred. Due to the lower $\eta$ value of ${ }^{233} \mathrm{U}$, compared to ${ }^{239} \mathrm{Pu}$, and to the significantly lower heavy metal density of thorium, the breeding ratio achievable with thorium-based fuel in a fast reactor is typically smaller than that achievable with uranium-based fuel. The lower heavy metal density may also require loading a larger volume of fuel or shortening the cycle length to keep the core critical. Although the delayed neutron fraction of ${ }^{232} \mathrm{Th}$ is higher than that of ${ }^{238} \mathrm{U}$, thorium has a substantially lower fission cross-section and will generally contribute less to the overall delayed neutron fraction. The lower delayed neutron fraction of the $\mathrm{Th} / \mathrm{U}$ fuel cycle compared to the $\mathrm{U} / \mathrm{Pu}$ fuel cycle makes thoriumbased fuel more sensitive to reactivity insertion. However, due to the cross-section resonances occurring in a lower energy range for ${ }^{233} \mathrm{U}$ than for ${ }^{239} \mathrm{Pu}$ and ${ }^{235} \mathrm{U}$, better reactivity feedback performance can be obtained.

Table 2.1 Comparison of Uranium and Thorium Properties

\begin{tabular}{|l|l|l|}
\hline & Uranium & Thorium \\
\hline Natural abundance (Earth crust) & $4 \mathrm{ppm}$ & $13 \mathrm{ppm}$ \\
\hline Fissile isotope & $\mathrm{U}-235$ & None \\
\hline Major bred fissile isotopes & $\mathrm{Pu}-239, \mathrm{Pu}-241$ & $\mathrm{U}-233$ \\
\hline Density (pure metal), g/cc & 19.1 & 11.7 \\
\hline \multirow{2}{*}{ Effective delayed neutron fraction } & $\begin{array}{c}\mathrm{U}-235: 0.0065 \\
\mathrm{U}-238: 0.0157\end{array}$ & $\begin{array}{c}\text { Th-232: } 0.022 \\
\mathrm{U}-233: 0.0027\end{array}$ \\
\hline
\end{tabular}




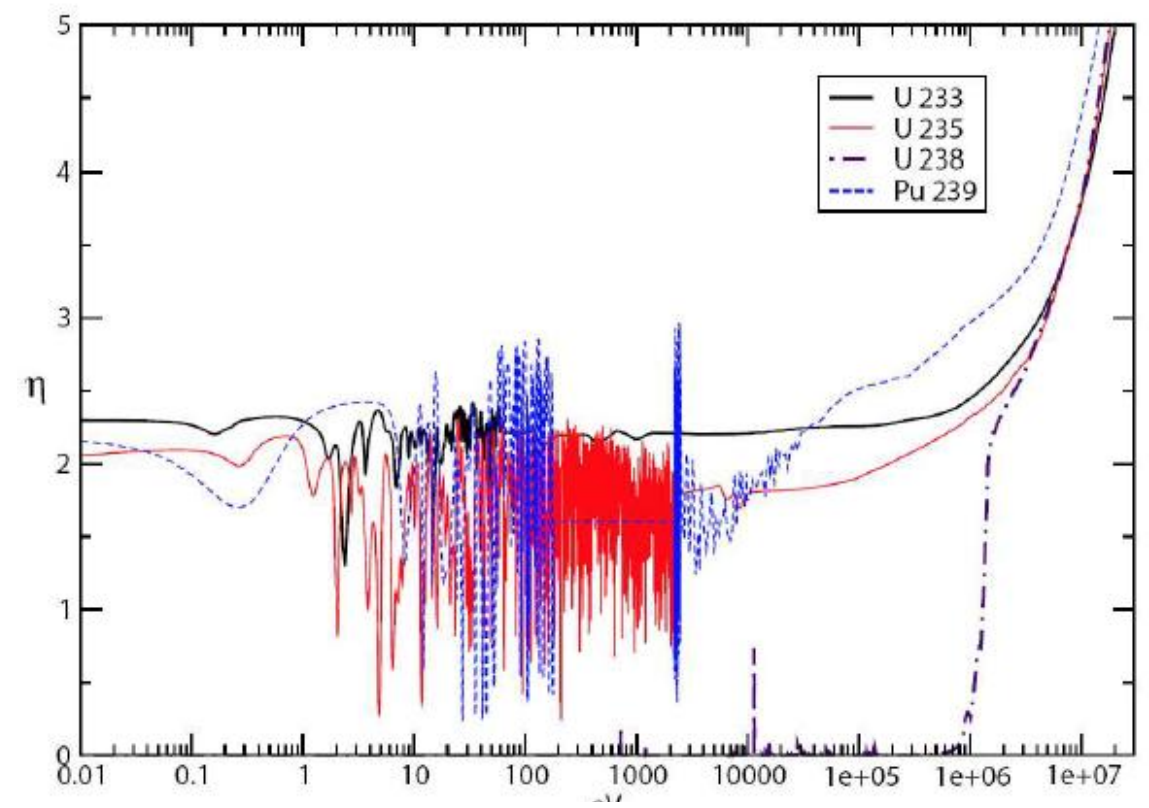

Figure 2.1 $\eta$ Evolution for some Major Actinides

\subsection{Design Objectives and Requirements}

The primary objective of this study is to assess the feasibility of transitioning a sodium-cooled fast reactor from uranium-based fuel to thorium-based fuel within the same fast reactor core geometry to allow for extending the use of an installed fast reactor technology base. The fuel conversion approaches must meet the original design constraints initially adopted in the SFR core concept with the uranium-based fuel and retain the favorable inherent safety features without changing the mechanical and physical design parameters: i.e., the uranium-based and thorium-based fuels must be able to co-exist in the core during the transition period until the core is entirely filled with thorium-based fuel.

The feasibility of the fuel conversion from uranium-based to thorium-based fuel was studied using the $100 \mathrm{MW}_{\mathrm{e}}$ Advanced Sodium-cooled Fast Reactor (AFR-100). The AFR-100 was developed targeting the emerging electricity markets where a clean, secured electricity resource is required but a large-scale plant is not accommodated. The reactor is aimed to be sized for local small grids and transportable to the plant site from a factory. The AFR-100 core concept was developed using the U-Zr metallic fuel with the peak fast flux fluence limit of $6 \times 10^{23}$ neutrons $/ \mathrm{cm}^{2}$ and the desired bulk coolant outlet temperature of $550{ }^{\circ} \mathrm{C}$.

For consistency to the fuel form adopted in the reference AFR-100 core concept, the thorium-based fuel was also considered as a metal fuel. Uranium-based metallic fuel requires additional alloy such as $\mathrm{Zr}$ or Mo to insure the fuel dimensional stability and to increase its solidus temperature. However, the thorium metal fuel does not need to be alloyed with $\mathrm{Zr}$ because its face centered cubic crystal structure is less prone to irradiation swelling than un-alloyed uranium [11-12]. When thorium needs to be mixed with fissile material, it is theoretically possible to use Th-Pu, Th-TRU, Th-LEU or Th- 
${ }^{233} \mathrm{U}$. In this study, TRU was preferred to plutonium because of the proliferation concern of separating plutonium from minor actinides. The Th-LEU fuel option appears unattractive compared to the Th-TRU fuel option because the maximum uranium enrichment is limited to $20 \%$. In order to achieve sufficient fissile loading with Th-LEU, the LEU would need to account for at least $70 \%$ of the total heavy metal loading while thorium would account for no more than $30 \%$. The last fuel type mentioned, $T h-{ }^{233} \mathrm{U}$, is currently unpractical because of the lack of significant ${ }^{233} \mathrm{U}$ reserves, which can only be produced as a result of thorium irradiation. In the future, use of $\mathrm{Th}^{2}-{ }^{23} \mathrm{U}$ fuel could be envisioned in a multi-stage fuel cycle. ${ }^{232} \mathrm{Th}$ and Th-TRU metal fuels are the primary fuel forms considered for the present study. However, the feasibility of the Th-LEU fuel option was also assessed as an alternative option. The density of ${ }^{232} \mathrm{Th}$ is taken to be 11.7 $\mathrm{g} / \mathrm{cm}^{3}$ and that of Th-TRU is taken to be $13.4 \mathrm{~g} / \mathrm{cm}^{3}$, which corresponds to approximately $20 \mathrm{wt} \%$ of TRU.

The fuel residence time in the core is limited by the fuel performance parameters such as Cumulative Damage Fraction (CDF), cladding strain, hoop stress, etc. However, the allowable fuel residence time was indirectly measured in this study using the peak fast flux fluence of the fuel cladding. Although the irradiation experience in FFTF [13] showed that cladding breach and duct elongation with HT-9 cladding were not observed up to a fast fluence of $\sim 4 \times 10^{23}$ neutrons $/ \mathrm{cm}^{2}$, the peak fast fluence of $6 \times 10^{23}$ neutrons $/ \mathrm{cm}^{2}$ from the reference AFR-100 design was adopted as the fast fluence limit for the thoriumbased fuels. This extended limit is based on the expectation that advanced cladding material for ultra-high burnup will be more resistant to irradiation damage. In addition, without further assessment of the irradiation performance of the thorium-based fuels, the fuel smear density and burnup axial expansion are taken to be respectively $75 \%$ and $8 \%$, the same as for $\mathrm{U}-10 \mathrm{Zr}$ fuel.

Other design requirements are taken to be the same as those of the reference AFR100 core. A reactor capacity factor of $90 \%$ is assumed for reactor maintenance. In this study, the coolant inlet and bulk outlet temperatures are assumed to be $395^{\circ} \mathrm{C}$ and $550^{\circ} \mathrm{C}$, respectively, which results in the mixed-coolant temperature rise across the core of $155^{\circ} \mathrm{C}$. Due to the high coolant temperature, a high thermal efficiency compared to a conventional metallic sodium-cooled fast reactor is expected and is assumed to be $40 \%$. The total thermal power of the AFR-100 core is $250 \mathrm{MW}_{\text {th }}$.

\subsection{Computation Methods}

The ANL suite of fast reactor analysis code system was used for the neutronics design. Fuel cycle analysis was performed with the DIF3D/REBUS-3 code system. Region-dependent multi-group neutron cross section sets generated for a typical metallic fueled sodium-cooled fast reactor under the USDOE Integral Fast Reactor (IFR) program were utilized in this study.

Using three-dimensional hexagonal-z geometry model, fuel cycle analyses were performed. Material thermal expansion at operating condition is modeled by adjusting the hexagonal pitch, axial meshes, and the fuel and structure volume fractions appropriately. The structural materials are not fixed in this study, but it is expected that the thermal expansion properties of the advanced structural materials are not significantly different 
from SS-316 or HT-9. Thus, the radial and axial thermal expansions were assumed to be the same as SS-316 and HT-9.

For U-Zr metal fuel, the irradiation induced swelling proceeds rapidly with burnup. The U-Zr metal fuel slug grows fully during the initial 1-2\% burnup. Beyond this burnup the metal fuel slug contacts the cladding and grows axially to $\sim 8 \%$ with a smeared density fuel of $75 \%$. Since no data was available regarding the swelling of thorium based metal fuel, the swelling behavior was assumed to be the same as for U-Zr fuel. In the fuel cycle analysis performed with the REBUS-3 code, the irradiation induced swelling of the metal fuel was modeled by a uniform axial growth of $8 \%$ and the bond sodium was pushed into the region above the fuel slug. However, since the irradiation induced swelling does not occur when the reactor starts with fresh fuel, the core performance characteristics of the beginning of the cycle (BOC) and beginning of life (BOL) are slightly inaccurate and would need to be separately evaluated by ignoring the irradiation induced swelling. Results reported in [1] show that this error is small $(<100 \mathrm{pcm})$ and can be neglected for this preliminary study.

The reactor effective delayed neutron fraction and prompt neutron lifetime are determined using the VARI3D perturbation code and the coolant void coefficient, fuel temperature coefficient and radial and axial expansion coefficients are determined by the direct differences in the eigenvalues for the nominal and perturbed conditions using the DIF3D code. Perturbed cross-section sets using 33-energy groups based on ENDF/B.VII database are used to calculate the reactivity feedback coefficients.

Reactor orifice zoning and flow allocation were determined through steady-state thermal-hydraulic analyses. Heating rates for thermal-hydraulic calculations were determined by neutronics calculations. A region-dependent 9-group neutron cross-section set was used. Gamma production and heating could not be accounted for because of the lack of data for ${ }^{232} \mathrm{Th}$ and ${ }^{233} \mathrm{U}$. This results in inaccurate temperature estimates in the region containing no heavy metal (reflector, shield and control assemblies). However, this approximation is not expected to have any major impact on the core performance since the coolant flow rate in those assemblies is typically in separated orifice groups and therefore can be easily adjusted. Neutron flux calculations were performed using the triangular-z finite difference option of the DIF3D code. The neutron heating distribution was determined by multiplying the neutron flux by the neutron KERMA factors. The total heating rate was appropriately normalized to the reactor power.

The sub-channel analysis code SE2-ANL was employed for whole core temperature calculations. SE2-ANL is a modified version of the SUPERENERGY-2 [14] thermalhydraulic code interfaced with ANL heating calculations. The SUPERENERGY-2 code is a multi-assembly, steady-state sub-channel analysis code designed specifically to perform efficient calculations of the detailed core-wide coolant temperature profiles in sodium cooled fast reactor core geometries. At ANL, reactor hot spot analysis methods as well as fuel and cladding temperature calculation models have been added to the original version of SUPERENERGY-2. Both nominal and $2 \sigma$ temperatures are calculated for the fuel and cladding. The nominal fuel and cladding temperatures are obtained by solving a steady-state one-dimensional conduction equation. The $2 \sigma$ temperatures are calculated using the semi-statistical method. 
The thermal margins of the AFR-100 core were evaluated by comparing the peak cladding inner wall temperature and fuel centerline temperature to the fuel-cladding eutectic temperature and fuel melting temperature, respectively. The fuel-cladding eutectic temperature is constrained by the fission products concentration in the fuel and by the diffusion rate of those fission products within the fuel [15]. For thorium fuel, the fission product composition is expected to be comparable to that of uranium fuel and although the diffusion rate might be different there is no data available to estimate the fission product migration. The same fuel-cladding eutectic temperature as for uranium metal fuel is used for thorium metal fuel. In this study, the fuel-cladding eutectic and the maximum fuel temperatures were assumed to be $700^{\circ} \mathrm{C}$ and $1200^{\circ} \mathrm{C}$, respectively. The coolant inlet temperature being assumed to be $395^{\circ} \mathrm{C}$, the average flow rate was determined such that the coolant temperature rise across the core is $155^{\circ} \mathrm{C}$.

The inherent safety features of AFR-100 core are assessed using the integral reactivity parameters of the quasi-static reactivity balance analysis. This method can provide indication of the necessary conditions of inherent safety features but not the sufficient conditions. Additional safety analyses based on various accident scenarios would be required to assure that the AFR-100 reactor designs proposed are inherently safe.

\subsection{AFR-100 Core Concept}

Figure 2.2 shows the radial core layout of the AFR-100, which consists of 150 fuel assemblies, 48 radial reflector assemblies and 54 radial shield assemblies. There are also ten primary control assemblies and three secondary control assemblies. The active core is divided into three different enrichment zones: 30 assemblies for the inner core, 48 assemblies for the middle core and 72 assemblies for the outer core. The fuel assemblies contain 91 fuel pins arranged in a triangular pitch array. The fuel pin diameter and cladding thickness are $1.49 \mathrm{~cm}$ and $0.5 \mathrm{~mm}$, respectively. The active core height is 110 $\mathrm{cm}$ and the overall assembly height is $302.3 \mathrm{~cm}$ including the lower reflector, shield and fuel handling structures. The dimensions of all the assemblies are the same as those used in the reference AFR-100 design [1].

In the reference AFR-100 design, different fuel enrichments are used in the axial and radial core regions in order to achieve a flat power distribution, 30 years operation and a small burnup reactivity swing with no refueling or shuffling. Figure 2.3 shows the relative uranium enrichment distribution in the reference AFR-100 core concept for which the average fuel enrichment is $13.47 \%$. 


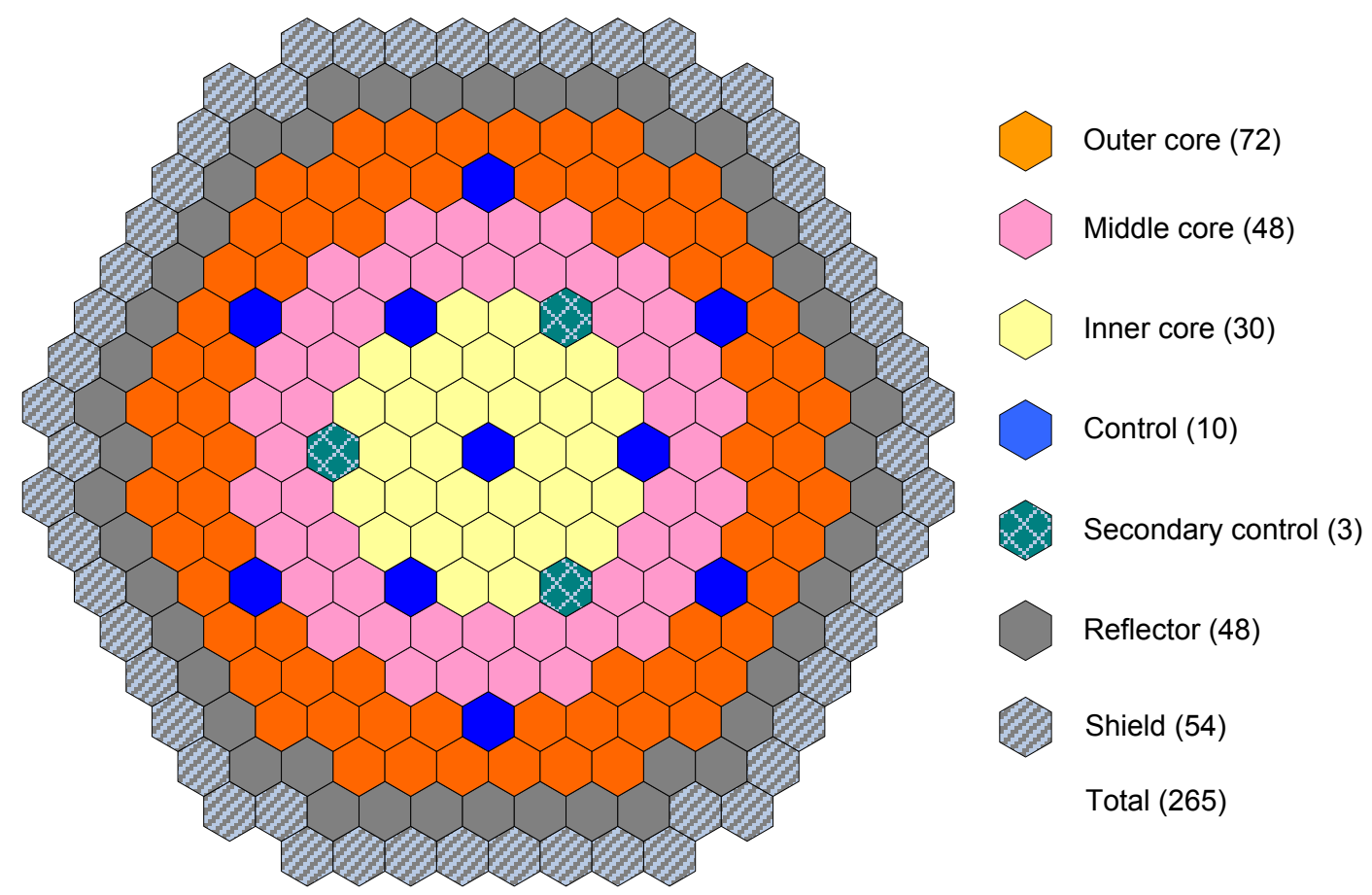

Figure 2.2 Radial Core Layout of AFR-100 Core

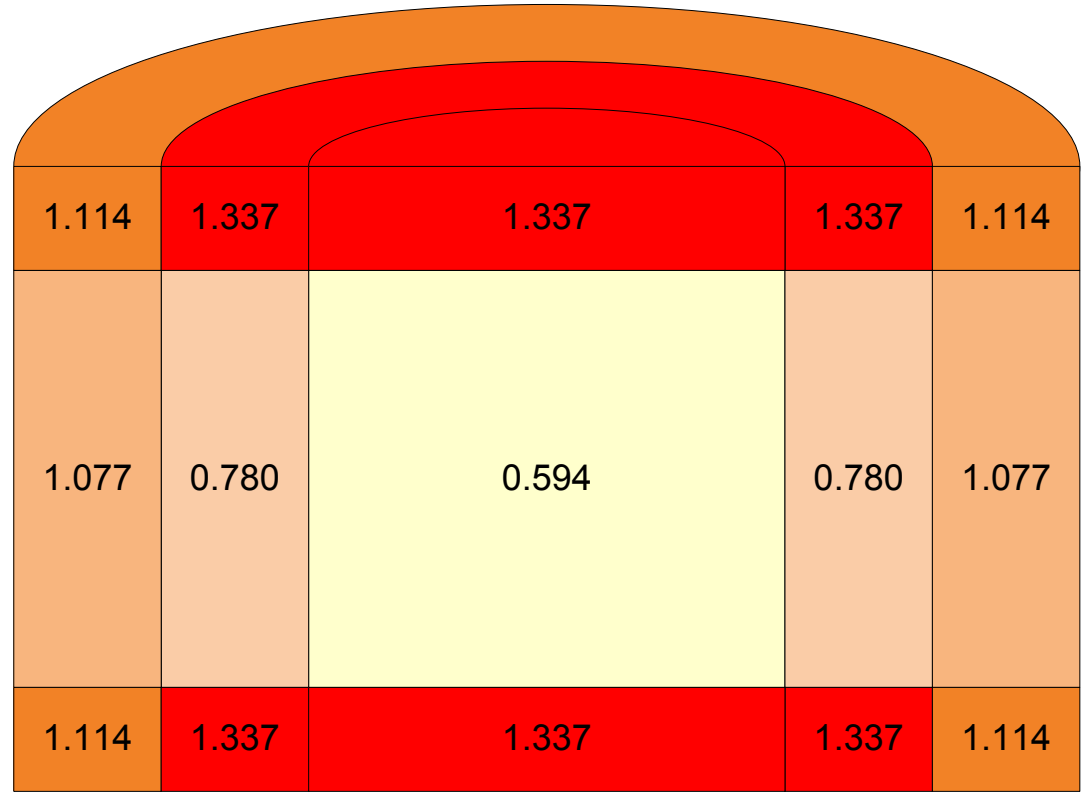

Figure 2.3 Relative Uranium Enrichment Distribution in the Reference AFR-100 Core 


\section{Fuel Conversion Scenarios}

Various fuel conversion scenarios were assessed in this study and three major approaches are introduced in this section: 1) progressive fuel conversion without fissile support, 2) progressive fuel conversion with fissile support, and 3) whole core fuel conversion with fissile support.

For the case of the progressive fuel conversion without fissile support, the AFR-100 core is operated for a given number of cycles and a fraction of the original uranium-based fuel assemblies is replaced with thorium-based fuel assemblies. The original uraniumbased fuel assemblies and the thorium-based fuel assemblies co-exist during the transition cycles and after a few fuel cycles the core is entirely loaded with thorium-based fuel assemblies. In this case, the fresh thorium-based fuel is made of pure thorium: i.e., the fresh fuel does not contain any fissile materials. This scenario was developed with the expectation that the core could maintain criticality by breeding ${ }^{233} \mathrm{U}$ in the thorium-based fuel (i.e., achieve a breed-and-burn mode with thorium-based fuel) although the fresh fuel does not contain fissile material. For this scenario, the timing of the fuel conversion and number of assemblies replaced play major roles in maintaining criticality.

The case of the progressive fuel conversion with fissile support is similar to the previous case except that the fresh thorium-based fuel contains fissile material. This scenario was developed because the core performance characteristics of the breed-andburn operation with thorium-based fuel were impractical $[16,17]$. In this study, the TRU recovered from the Pressurized Water Reactor (PWR) used nuclear fuel with a discharge burnup of $50 \mathrm{GWd} / \mathrm{t}$ was considered as fissile material and the TRU vector used is provided in Table 3.1 .

Table 3.1 Transuranics V
\begin{tabular}{|l|l|}
\hline Isotope & Weight \% \\
\hline${ }^{237} \mathrm{~Np}$ & $4.79 \%$ \\
${ }^{238} \mathrm{Pu}$ & $2.21 \%$ \\
${ }^{239} \mathrm{Pu}$ & $47.71 \%$ \\
${ }^{240} \mathrm{Pu}$ & $22.90 \%$ \\
${ }^{241} \mathrm{Pu}$ & $8.42 \%$ \\
${ }^{242} \mathrm{Pu}$ & $6.80 \%$ \\
${ }^{241} \mathrm{Am}$ & $5.61 \%$ \\
${ }^{242 \mathrm{~m}} \mathrm{Am}$ & $0.01 \%$ \\
${ }^{243} \mathrm{Am}$ & $1.54 \%$ \\
\hline
\end{tabular}

The last case is the whole core fuel conversion with fissile support. Compared to the previous two cases, all the fuel assemblies are replaced at once with thorium-based fuel assemblies: i.e., a one-batch fuel scheme is adopted and the core does not have transition cycles. This case was considered because the reference AFR-100 core concept was developed with a similar one-batch fuel management scheme. In addition, LEU is used as the supporting fissile material for consistency. The LEU enrichment is taken to be $20 \%$ or less. In order to improve the ${ }^{233} \mathrm{U}$ breeding ratio, a heterogeneous core configuration was 
considered rather than a homogeneous core configuration. Heterogeneous core configuration is typically achieved by loading LEU in driver assemblies and pure thorium fuel in the blanket assemblies. However, due to the challenge of cooling the core as a result of the high power variation occurring in the blanket assemblies, the separation of the LEU and pure thorium fuel was considered axially: i.e., the fuel pins are made of several layers of LEU and thorium. Use of radial blanket assemblies made only of pure thorium would have required changing the mode of operation assumed and stopping the reactor every few years in order to shuffle the blanket assemblies.

\subsection{Progressive Fuel Conversion Scenario without Fissile Support}

The progressive fuel conversion scenario without fissile support was developed with the expectation of a breed-and-burn mode operation in a thorium fuel cycle: i.e., the reference core is operated for a given number of cycles and then a fraction of the original uranium-based fuel assemblies are replaced with fuel assemblies made of pure ${ }^{232} \mathrm{Th}$; the neutrons leaking from the uranium-based fuel assemblies are used to breed ${ }^{233} \mathrm{U}$ in the thorium-based fuel assemblies.

In order to minimize the number of transition cycles needed to achieve fuel conversion, it is desirable to replace as many assemblies as possible. Under the current scenario, the number of fuel assemblies which can be replaced at once is however restrained by the excess reactivity of the reference AFR-100 core when the fuel conversion starts. It is noted that the core may become sub-critical by replacing too many uranium-based fuel assemblies with thorium-based fuel assemblies because the thoriumbased fuel assemblies do not contain any fissile material.

A sensitivity study was performed by varying the starting time of the fuel conversion. In this sensitivity study, the reference AFR-100 core is operated with uranium-based fuel assemblies for some time and then 30 out of the 150 fuel assemblies are replaced with fresh thorium-based fuel assemblies. The core performance was evaluated starting the fuel conversion after operation of the reference AFR-100 core for 2, 6, 10, 14, 18 or 22 years and for the replacement thorium-based fuel assemblies occurring in the inner, middle or outer core regions. The $\mathrm{k}_{\text {eff }}$ evolution for the core configurations with the fuel assemblies being replaced in the inner, middle and outer core regions is shown in Figures 3.1, 3.2 and 3.3, respectively. In these figures, the core multiplication factor of the reference AFR-100 with the original uranium-based fuel assemblies is also provided to show the excess reactivity of the core when the fuel conversion starts. 


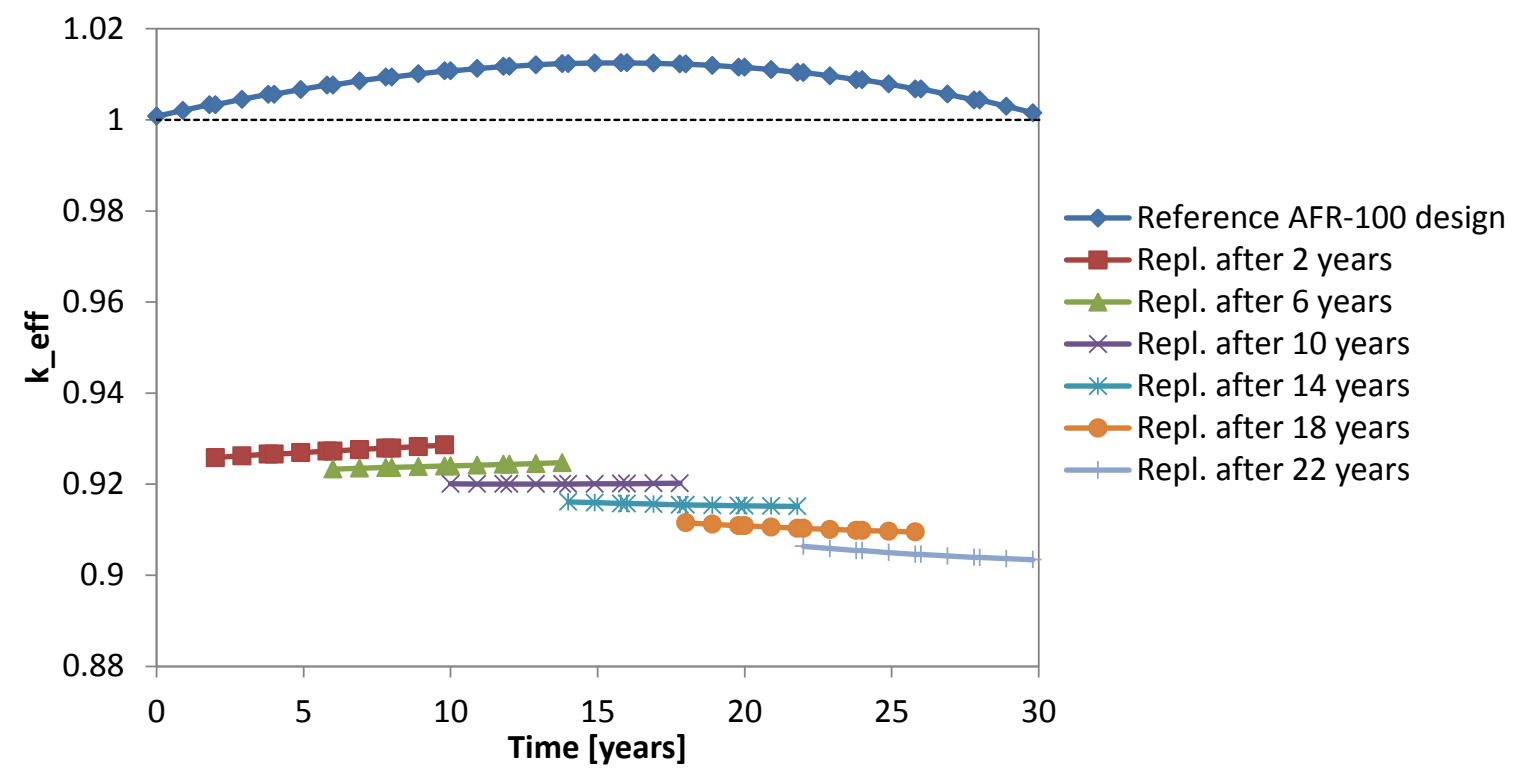

Figure 3.1 $\mathrm{k}_{\text {eff }}$ Evolution for the Fuel Replacement Occurring in the Inner Core Region

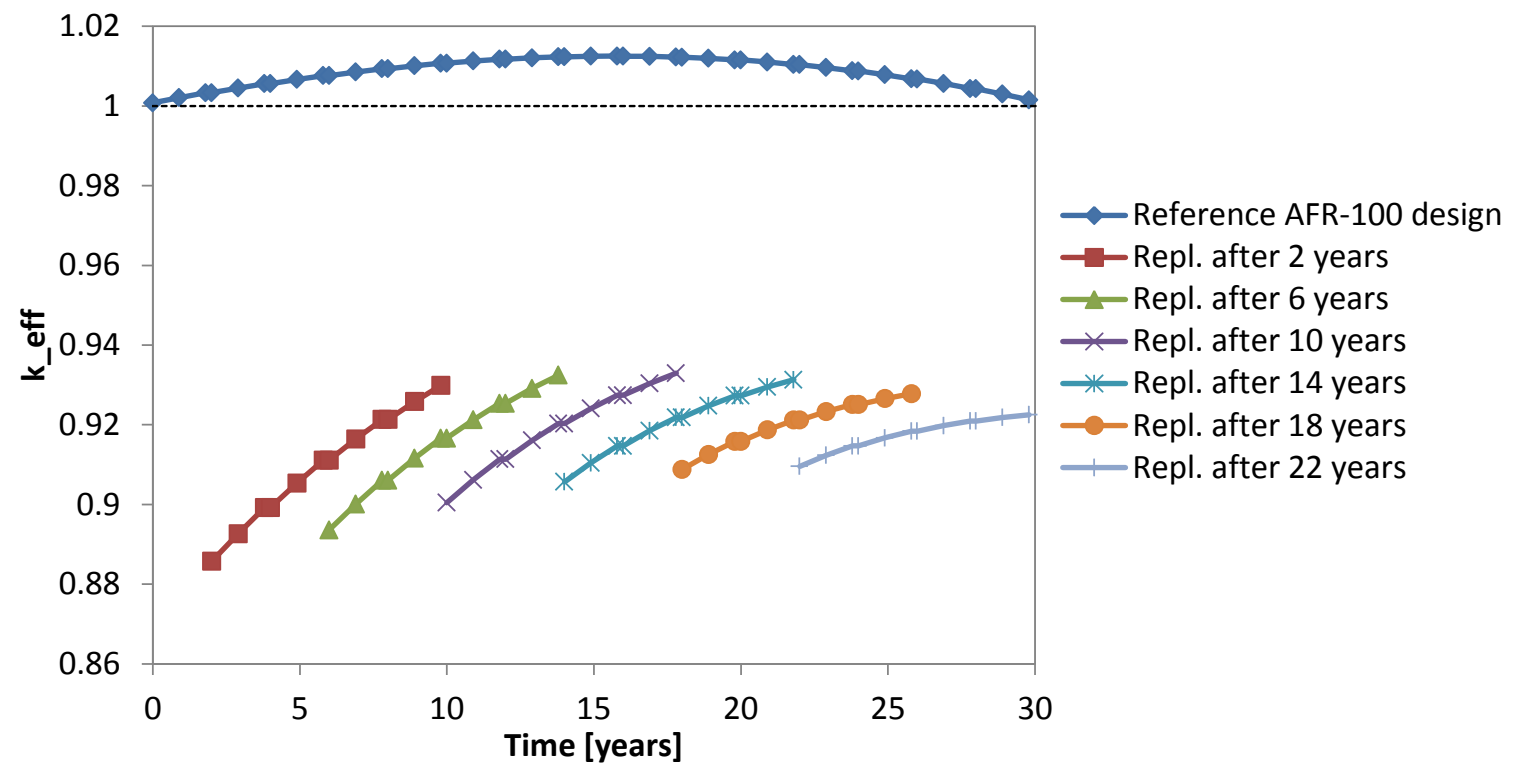

Figure 3.2 $\mathrm{k}_{\text {eff }}$ Evolution for the Fuel Replacement Occurring in the Middle Core Region 


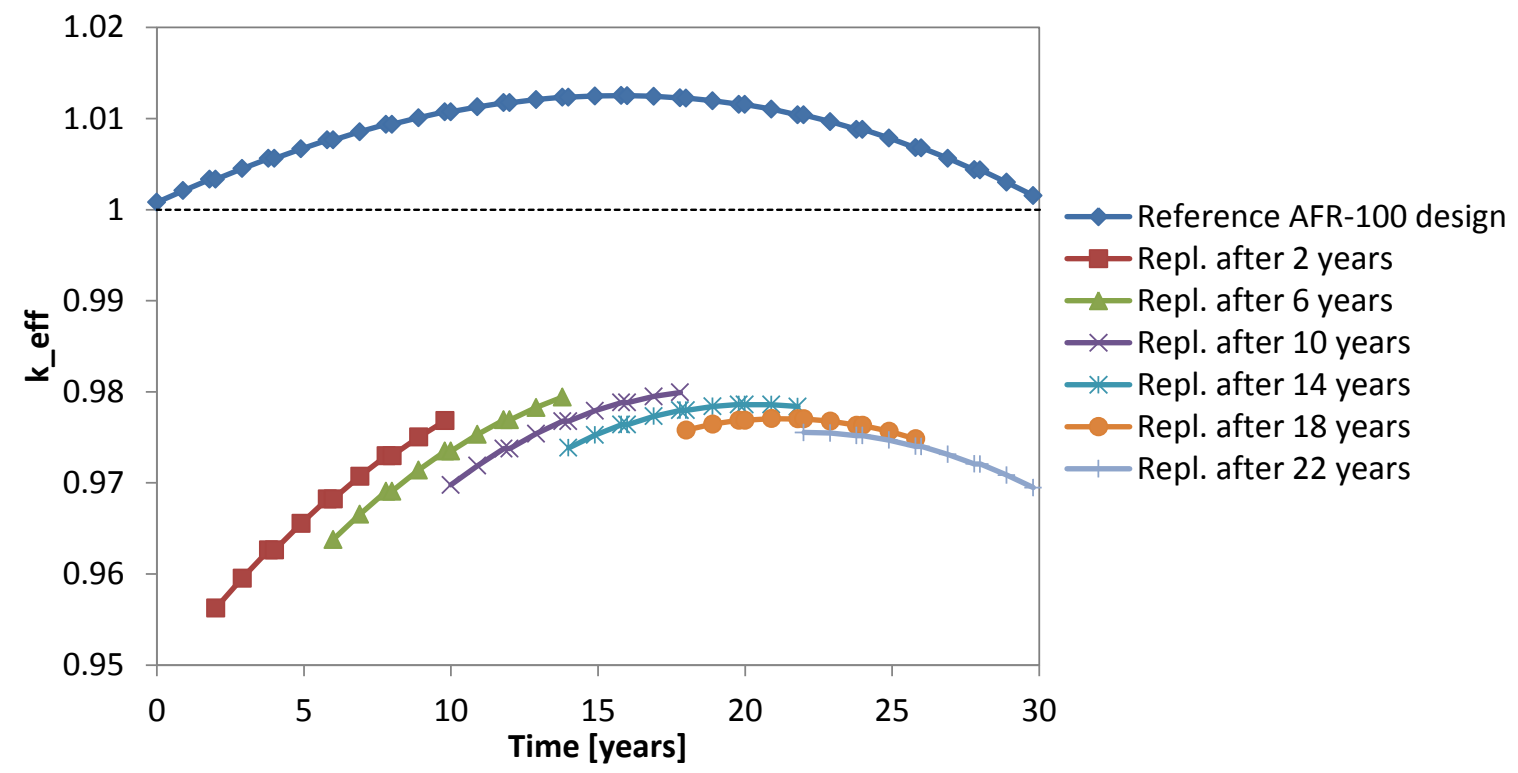

Figure $3.3 \mathrm{k}_{\mathrm{eff}}$ Evolution for the Fuel Replacement Occurring in the Outer Core
Region

None of these configurations resulted into a critical core after replacing 30 of the original uranium-based fuel assemblies with thorium-based fuel assemblies. It is observed that the core is subcritical although the fuel conversion starts when the excess reactivity of the AFR-100 reaches its maximum value after 17 years of operation with the original uranium-based fuel assemblies. At this point in time the power is mostly generated in the inner and middle core region and therefore, replacing assemblies in any of those regions has a significant impact on the core reactivity. Although replacing assemblies located in the outer core region results in a smaller reactivity drop, the maximum excess reactivity of the reference AFR-100 core is so small that the core becomes subcritical nevertheless.

The result of the sensitivity study indicates that replacing 30 assemblies out of 150 original fuel assemblies is too many. Thus, an additional sensitivity study was performed to search for the number of replacement of the fuel assemblies to maintain criticality. By replacing only a few original uranium-based fuel assemblies with thorium fuel assemblies, in the outer core region, it is possible to obtain a critical core configuration.

These sensitivity results, shown in Figure 3.4, indicate that the progressive fuel conversion of the AFR-100 core is impractical without fissile support. The core can maintain criticality by replacing at most 9 uranium-based fuel assemblies, but the corresponding cycle length is only 4 years, resulting in a discharge burnup significantly smaller than achieved with the reference AFR-100 core. Overall, this approach based solely on the use of pure thorium appears unattractive and as a result no thermalhydraulics or reactivity feedback coefficient study was performed for it. 


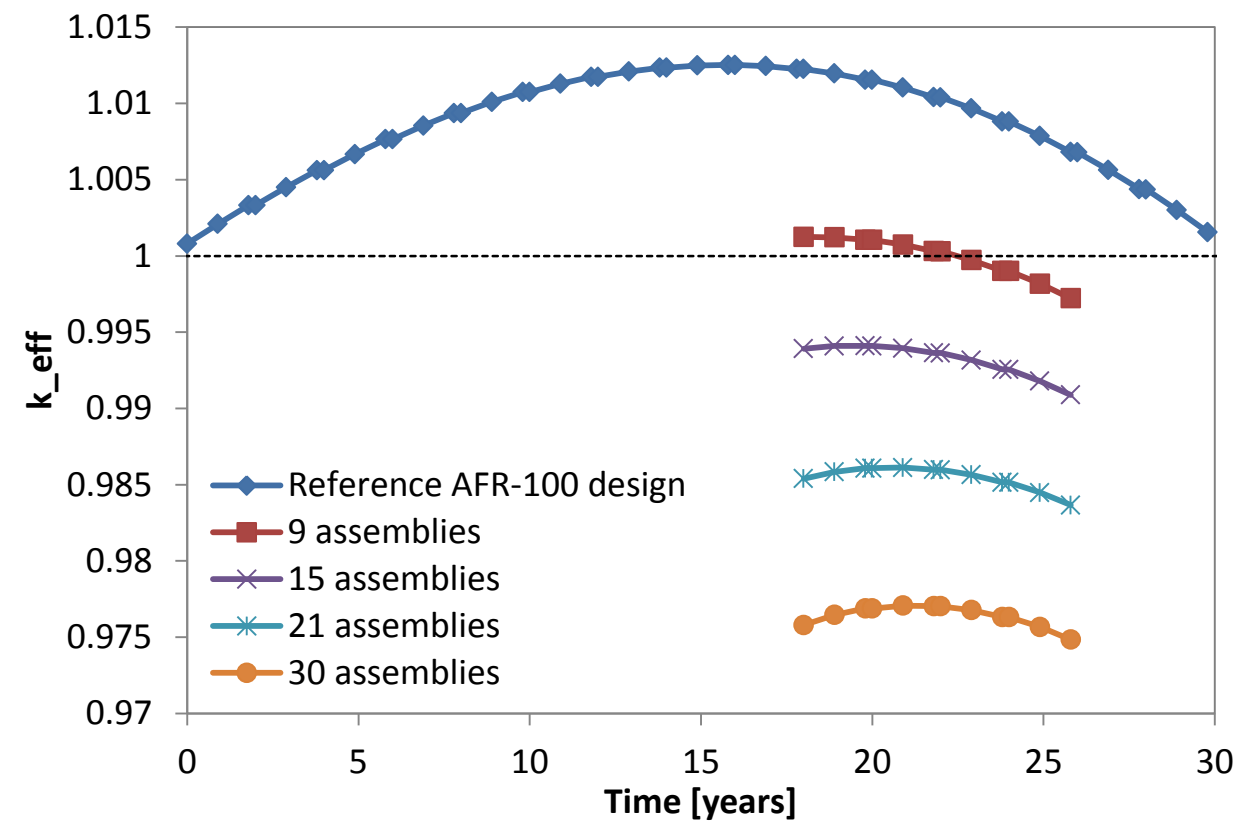

Figure $3.4 k_{\text {eff }}$ Evolution for Various Number of Assemblies Replaced in the Outer Core Region

\subsection{Progressive Fuel Conversion Scenario with Fissile Support}

The same enrichment zoning strategy as in the reference AFR-100 design is used in order to obtain an acceptable radial power distribution and burnup reactivity swing. Figure 2.3 shows the TRU weight coefficients used in each core region, relative to the average TRU weight fraction.

After all the original fuel assemblies have been replaced with Th-TRU fuel assemblies, the same fuel replacement strategy is continued and after a few cycles an equilibrium mode of operation is reached. The core layout for a 4-batches strategy is shown in Figure 3.5. In order to conserve a $1 / 3$ core symmetry with a 4-batches strategy, batches 1 and 3 are made of 39 fuel assemblies while batches 2 and 4 are made of 36 fuel assemblies. 


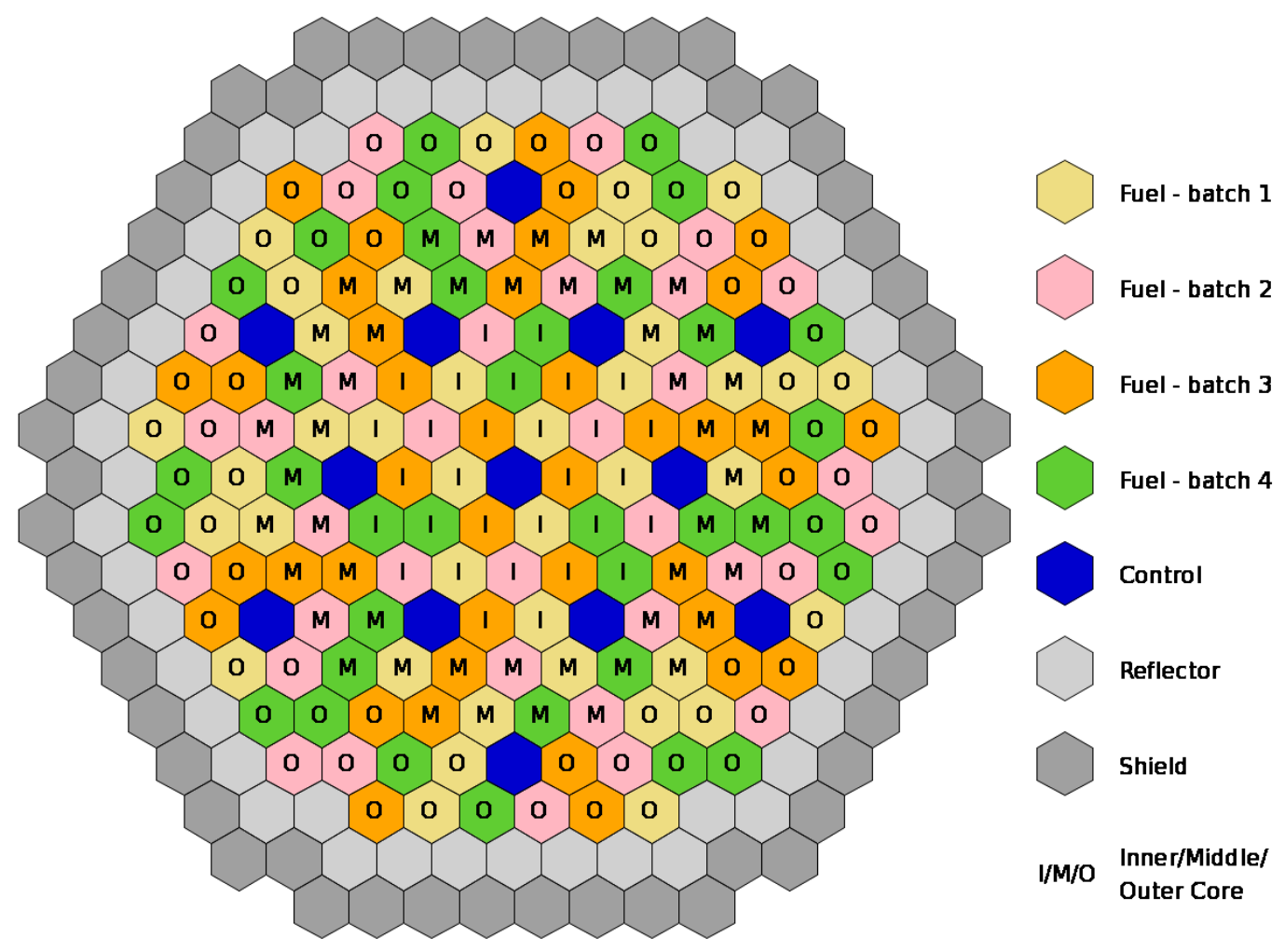

Figure 3.5 Th-TRU Fueled AFR-100 Core Layout for a 4-batches Strategy

The reference AFR-100 core initially loaded with LEU assemblies is first operated for 24 years. Batch 1 (Figure 3.5) is then replaced with Th-TRU fuel assemblies having an average TRU weight fraction of $18.6 \%$. The time at which the first fuel replacement occurs was determined by a sensitivity study. It corresponds to the longest cycle length allowing maintaining the core critical during the transition period. The TRU weight fraction used and cycle length of the succeeding cycles are identical to those of the equilibrium cycles. Following the first fuel replacement, the core is operated with 7.04 years cycles at the end of which another fuel batch is replaced. After five batch replacements ( $125 \%$ of the core volume), the equilibrium operation is reached. The $\mathrm{k}_{\mathrm{eff}}$ evolution is shown in Figure 3.6 for the transition period and a few cycles at equilibrium. The main core performance parameters are provided in Table 3.2. 


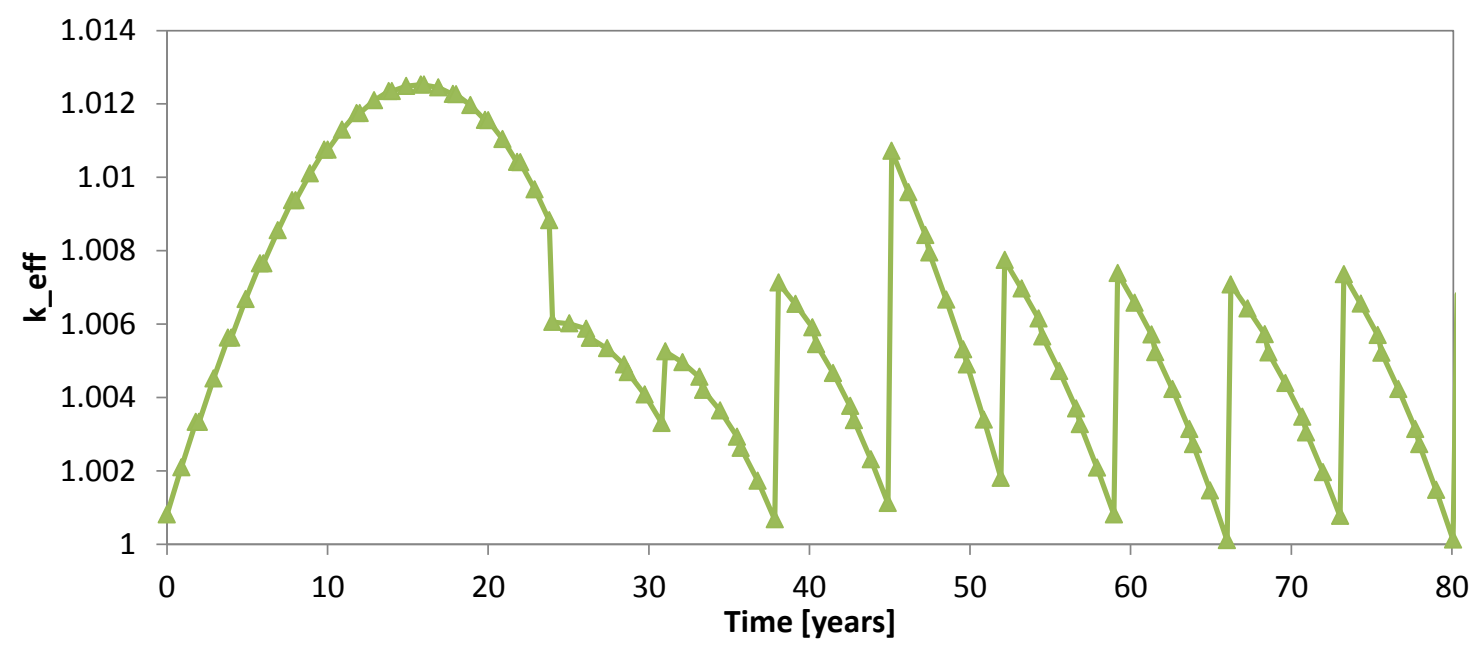

Figure 3.6 $\mathrm{k}_{\text {eff }}$ Evolution of the Th-TRU Fueled AFR-100 Core during Transition and at Equilibrium for a 4-batches Strategy

Table 3.2 Core Performance Parameters for the Th-TRU Fueled AFR-100

\begin{tabular}{|l|r|r|}
\hline Characteristic & Transition & Equilibrium \\
\hline Thermal power, MWt & 250 & 250 \\
\hline Refueling interval, yr & 24 then 7.04 & 7.04 \\
\hline Number of batches & 4 & 4 \\
\hline Fuel form & LEU \& Th-TRU & Th-TRU \\
\hline TRU fraction, wt\% & 18.6 & 18.6 \\
\hline Initial HM loading, $\mathrm{t}$ & 23.9 & 22.9 \\
\hline Burnup reactivity swing, $\% \Delta \mathrm{k}$ & 1.25 & 0.77 \\
\hline Specific power density, $\mathrm{MW} / \mathrm{t}$ & 10.5 & 10.9 \\
\hline Average power density, $\mathrm{W} / \mathrm{cm}^{3}$ & 58.3 & 58.3 \\
\hline Peak power density, $\mathrm{W} / \mathrm{cm}^{3}$ & 114.8 & 110.3 \\
\hline Radial power peaking factor & 1.45 & 1.32 \\
\hline Overall fissile breeding ratio & 0.92 & 0.96 \\
\hline Average discharge burnup, $\mathrm{GWd} / \mathrm{t}$ & 120.4 & 100.9 \\
\hline Peak discharge burnup, $\mathrm{GWd} / \mathrm{t}$ & 222.2 & 162.3 \\
\hline Peak fast fluence, $10^{23} \mathrm{n} / \mathrm{cm}^{2}$ & 9.00 & 5.52 \\
\hline
\end{tabular}

The second column of Table 3.2 corresponds to the core characteristics during the first four cycles, when LEU fuel assemblies are still present in the core. The burnup values and peak fast fluence provided in this column pertain to the LEU fuel only. It is observed that the average discharge burnup of the LEU fuel is larger than that of the reference AFR-100 design because of the longer residence time and higher enrichment. Subsequently, the peak fast fluence of the LEU fuel reaches $9.0^{*} 10^{23} \mathrm{n} / \mathrm{cm}^{2}$ which is 
significantly larger than the value currently demonstrated for HT-9 $\left(\sim 4.0^{*} 10^{23}\right)$ and the value assumed for the reference AFR-100 design $\left(6.0^{*} 10^{23}\right)$. This potential issue could be solved by performing the first fuel replacement after 15-20 years instead of 24 years. The burnup reactivity swing of the transition period, $1.15 \% \Delta \mathrm{k}$, is identical to that of the reference AFR-100 design and is occurring during the initial 24 years cycle. The following cycles have a smaller burnup reactivity swing. The radial power peaking factor during the transition period is 1.45 , approximately the same as that observed for the reference AFR-100 design, 1.44. The power production of each fuel assembly is shown in $\mathrm{MW}_{\text {th }}$ in Figure 3.7 at BOL and when the maximum radial power peaking occurs, at the end of the third cycle (37.8 years).

The initial heavy metal loading is slightly decreasing during the transition period because the Th-TRU heavy metal density is smaller than that of LEU fuel. Due to the lack of data regarding Th-TRU metal fuel characteristics, its density is assumed to be $13.4 \mathrm{~g} / \mathrm{cm}^{3}$ which corresponds approximately to $20 \mathrm{wt} \%$ TRU. Subsequently, the specific power density is increasing as LEU fuel is replaced with Th-TRU fuel.

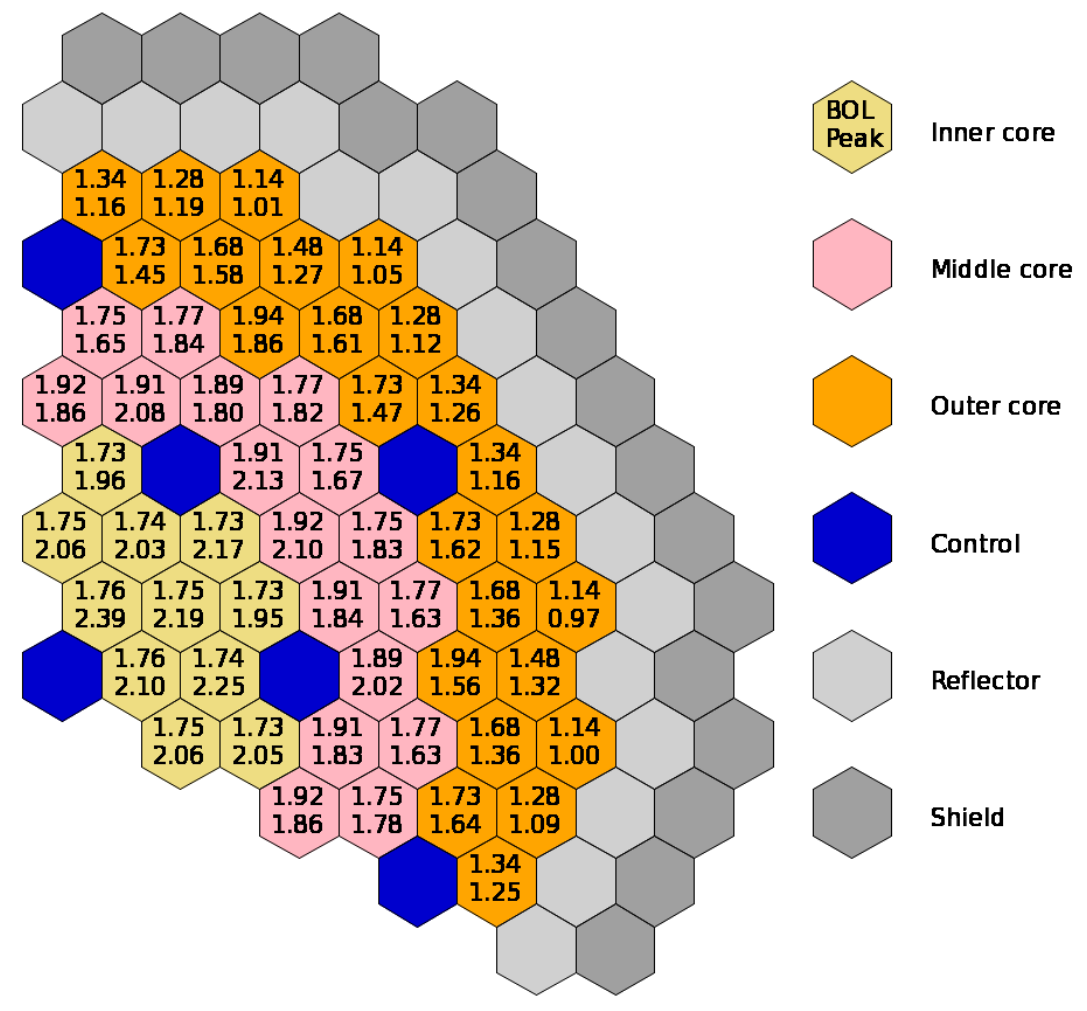

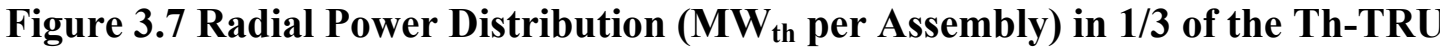 Fueled Core during Transition}

The $\mathrm{k}_{\text {eff }}$ evolution of the Th-TRU fueled core at equilibrium is 4-cycles periodic because of the 4-batches strategy. Very minor differences are observed among the four cycles, and the values provided in the last column of Table 3.2 correspond to the maxima and average values of those four equilibrium cycles. The burnup reactivity swing observed is only $0.77 \% \Delta \mathrm{k}$, and the average Th-TRU fuel discharge burnup is 100.9 
GWd/t. Due to the smaller discharge burnup and different power distribution, the peak fast fluence of the Th-TRU fuel at equilibrium is smaller than that of the LEU fuel during the transition period. It is also slightly smaller than that of the reference AFR-100 core for which the fuel is discharged at a similar burnup. The radial power distribution is represented in Figure 3.8 at BOC and EOC for the equilibrium cycle during which the maximum radial power peaking occurs. The power production of each assembly is provided in $\mathrm{MW}_{\text {th }}$ in this figure.

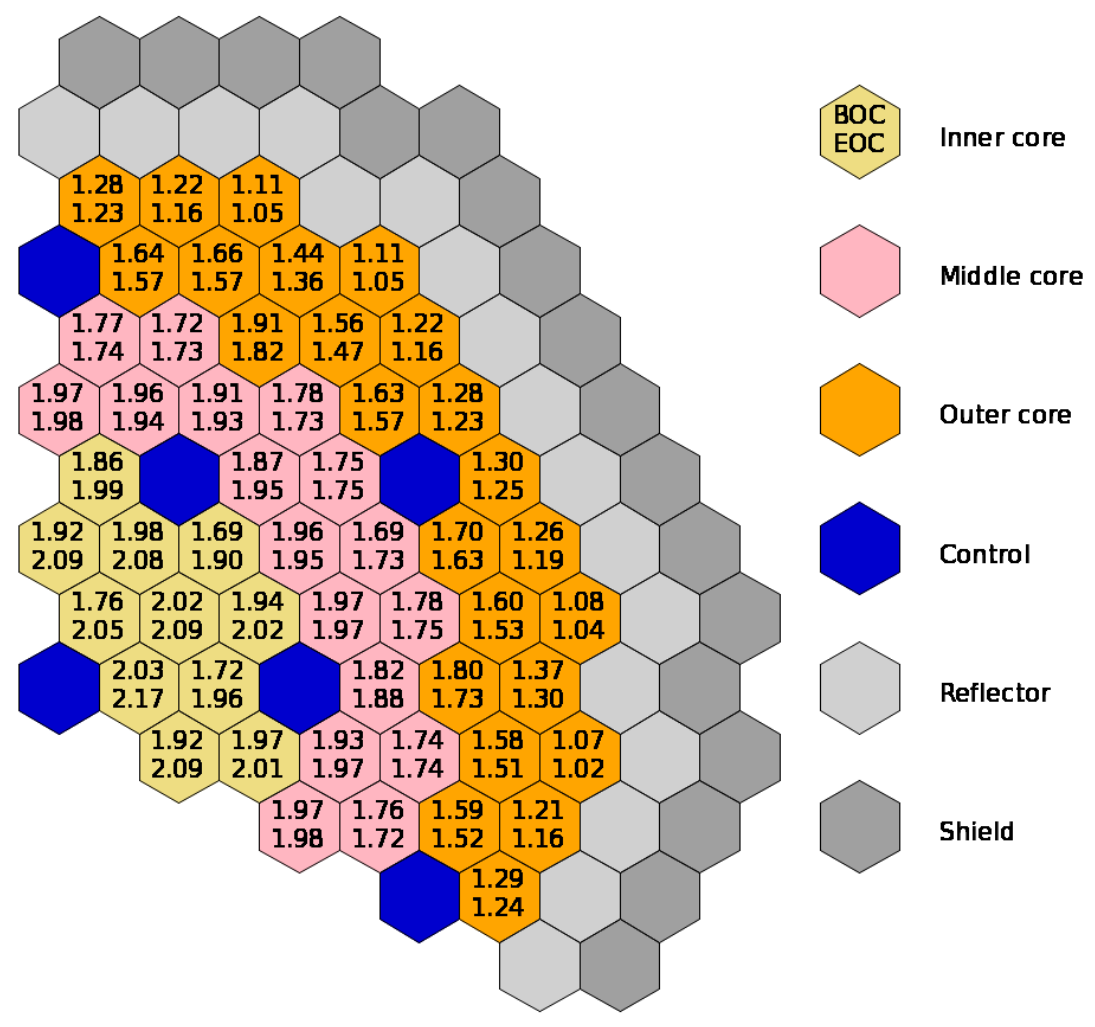

\section{Figure 3.8 Radial Power Distribution (MW ${ }_{\text {th }}$ per Assembly) in 1/3 of the Th-TRU Fueled Core at Equilibrium}

The heavy metal mass flow is provided in Table 3.3 for the first four cycles of the transition period and in Table 3.4 for four equilibrium cycles. It should be noted that there is a major difference between the transition period and the equilibrium period regarding the heavy metal charge of the first cycle. For the transition period the first charge corresponds to the entire core loading while for the equilibrium period it corresponds only to the fraction of fuel being replaced, which is approximately $25 \%$ of the core volume. During the four equilibrium cycles, corresponding to 28.16 years, about 2.4 tons of heavy metal is consumed. The mass of fissile plutonium loaded in the core is reduced by approximately 59\%, corresponding to a net consumption of 1.4 tons. About 2.0 tons of ${ }^{232} \mathrm{Th}$ are converted into ${ }^{233} \mathrm{U}$ of which 1.1 tons are discharged. On average, 
$662 \mathrm{~kg}$ of ${ }^{232} \mathrm{Th}$ and $151 \mathrm{~kg}$ of TRU are needed yearly to feed the Th-TRU fueled AFR100 core.

Table 3.3 Heavy Metal Mass Flow for the Transition Period of the Th-TRU fueled Core

\begin{tabular}{|c|r|r|r|r|r|r|r|r|r|r|}
\cline { 2 - 11 } \multicolumn{1}{c|}{} & \multicolumn{4}{c|}{ Charge [kg] } & \multicolumn{5}{c|}{ Discharge [kg] } \\
\hline Cycle \# & 1 & 2 & 3 & \multicolumn{1}{c|}{4} & Total & 1 & 2 & 3 & 4 & Total \\
\hline${ }^{232} \mathrm{Th}$ & - & 4852 & 4466 & 4852 & 14171 & 0 & 0 & 0 & 0 & 0 \\
\hline${ }^{233} \mathrm{U}$ & - & - & - & - & 0 & 0 & 0 & 0 & 0 & 0 \\
\hline${ }^{234} \mathrm{U}$ & - & - & - & - & 0 & 0 & 0 & 0 & 1 & 1 \\
\hline${ }^{235} \mathrm{U}$ & 3219 & - & - & - & 3219 & 420 & 333 & 278 & 230 & 1260 \\
\hline${ }^{236} \mathrm{U}$ & - & - & - & - & 0 & 72 & 75 & 89 & 86 & 322 \\
\hline${ }^{238} \mathrm{U}$ & 20685 & - & - & - & 20685 & 4893 & 4401 & 4605 & 4167 & 18065 \\
\hline${ }^{238} \mathrm{Pu}$ & - & 24 & 23 & 24 & 71 & 1 & 2 & 3 & 3 & 9 \\
\hline${ }^{239} \mathrm{Pu}$ & - & 525 & 491 & 525 & 1541 & 270 & 280 & 344 & 327 & 1221 \\
\hline${ }^{240} \mathrm{Pu}$ & - & 252 & 236 & 252 & 740 & 15 & 20 & 32 & 34 & 101 \\
\hline${ }^{241} \mathrm{Pu}$ & - & 93 & 87 & 93 & 272 & 1 & 1 & 1 & 2 & 4 \\
\hline${ }^{242} \mathrm{Pu}$ & - & 75 & 70 & 75 & 220 & 0 & 0 & 0 & 0 & 0 \\
\hline MA & - & 132 & 123 & 132 & 386 & 25 & 25 & 31 & 31 & 112 \\
\hline Total & 23904 & 5953 & 5495 & 5953 & 41304 & 5697 & 5138 & 5383 & 4879 & 21097 \\
\hline Fissile & 3219 & 618 & 577 & 618 & 5032 & 691 & 614 & 623 & 558 & 2486 \\
\hline
\end{tabular}

Table 3.4 Heavy Metal Mass Flow at Equilibrium for the Th-TRU Fueled Core

\begin{tabular}{|c|r|r|r|r|r|r|r|r|r|r|}
\cline { 2 - 12 } \multicolumn{1}{c|}{} & \multicolumn{4}{c|}{ Charge [kg] } & \multicolumn{5}{c|}{ Discharge [kg] } \\
\hline Cycle \# & 1 & 2 & 3 & 4 & Total & 1 & 2 & 3 & 4 & Total \\
\hline${ }^{232} \mathrm{Th}$ & 4852 & 4466 & 4852 & 4466 & 18637 & 4332 & 4007 & 4329 & 4010 & 16678 \\
\hline${ }^{233} \mathrm{U}$ & - & - & - & - & 0 & 277 & 249 & 278 & 249 & 1052 \\
\hline${ }^{234} \mathrm{U}$ & - & - & - & - & 0 & 21 & 18 & 21 & 18 & 77 \\
\hline${ }^{235} \mathrm{U}$ & - & - & - & - & 0 & 1 & 1 & 1 & 1 & 5 \\
\hline${ }^{236} \mathrm{U}$ & - & - & - & - & 0 & 1 & 1 & 1 & 1 & 3 \\
\hline${ }^{238} \mathrm{U}$ & - & - & - & - & 0 & 0 & 0 & 0 & 0 & 0 \\
\hline${ }^{238} \mathrm{Pu}$ & 24 & 23 & 24 & 23 & 94 & 35 & 33 & 36 & 33 & 137 \\
\hline${ }^{239} \mathrm{Pu}$ & 525 & 491 & 525 & 491 & 2032 & 230 & 223 & 229 & 224 & 906 \\
\hline${ }^{240} \mathrm{Pu}$ & 252 & 236 & 252 & 236 & 975 & 213 & 201 & 213 & 201 & 828 \\
\hline${ }^{241} \mathrm{Pu}$ & 93 & 87 & 93 & 87 & 358 & 21 & 20 & 21 & 20 & 81 \\
\hline${ }^{242} \mathrm{Pu}$ & 75 & 70 & 75 & 70 & 290 & 68 & 63 & 68 & 63 & 262 \\
\hline $\mathrm{MA}$ & 132 & 123 & 132 & 123 & 509 & 122 & 116 & 121 & 116 & 475 \\
\hline Total & 5953 & 5495 & 5953 & 5495 & 22895 & 5321 & 4932 & 5317 & 4935 & 20505 \\
\hline Fissile & 618 & 577 & 618 & 577 & 2390 & 529 & 493 & 529 & 493 & 2045 \\
\hline
\end{tabular}




\subsection{Whole Core Fuel Conversion Scenario with Fissile Support}

With this third approach, the core is operated with a single batch mode: no shuffling occurs and every fuel assembly is replaced with a fresh one when the reactor becomes subcritical. The fuel assemblies, loaded in the inner, middle and outer core region, as shown in Figure 2.2, are made of a different number of fuel layers and layer thicknesses. This core layout and mode of operation are similar to those of the reference AFR-100 design.

The AFR-100 core is entirely loaded with assemblies made of several $20 \%$ enriched uranium layers and several ${ }^{232} \mathrm{Th}$ layers. As shown in Figure 3.9, the inner, middle and outer core assemblies are made of 9, 7 and 7 layers, respectively. The total mass of ${ }^{235} \mathrm{U}$ required, $3442 \mathrm{~kg}$, is almost equal to the mass of ${ }^{235} \mathrm{U}$ required to start the reference AFR100 core, but due to the highest enrichment, the amount of SWU required is larger. The layer thicknesses have been chosen so as to obtain an acceptable radial power distribution and small burnup reactivity swing and to maintain the core critical for as long as possible without refueling or shuffling. At BOL the thorium represents about $25 \%$ of the total heavy metal mass. The $\mathrm{k}_{\mathrm{eff}}$ evolution for this core is shown in Figure 3.10 and the main core performance parameters are provided in Table 3.5.

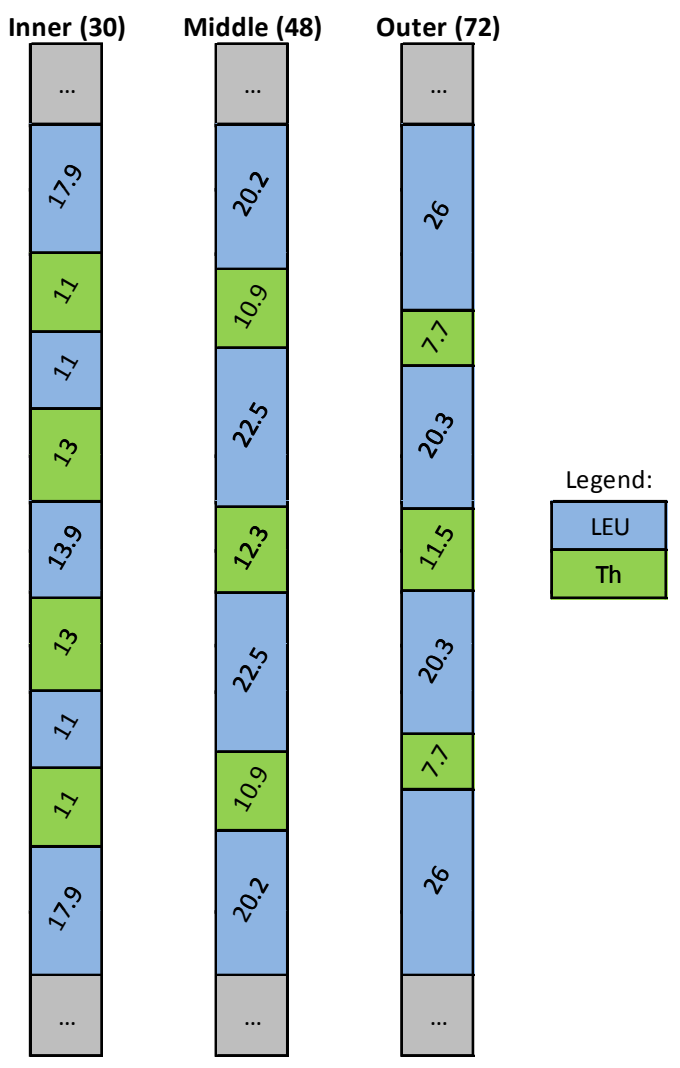

Figure 3.9 Inner, Middle and Outer Fuel Assemblies Layers (in cm) 


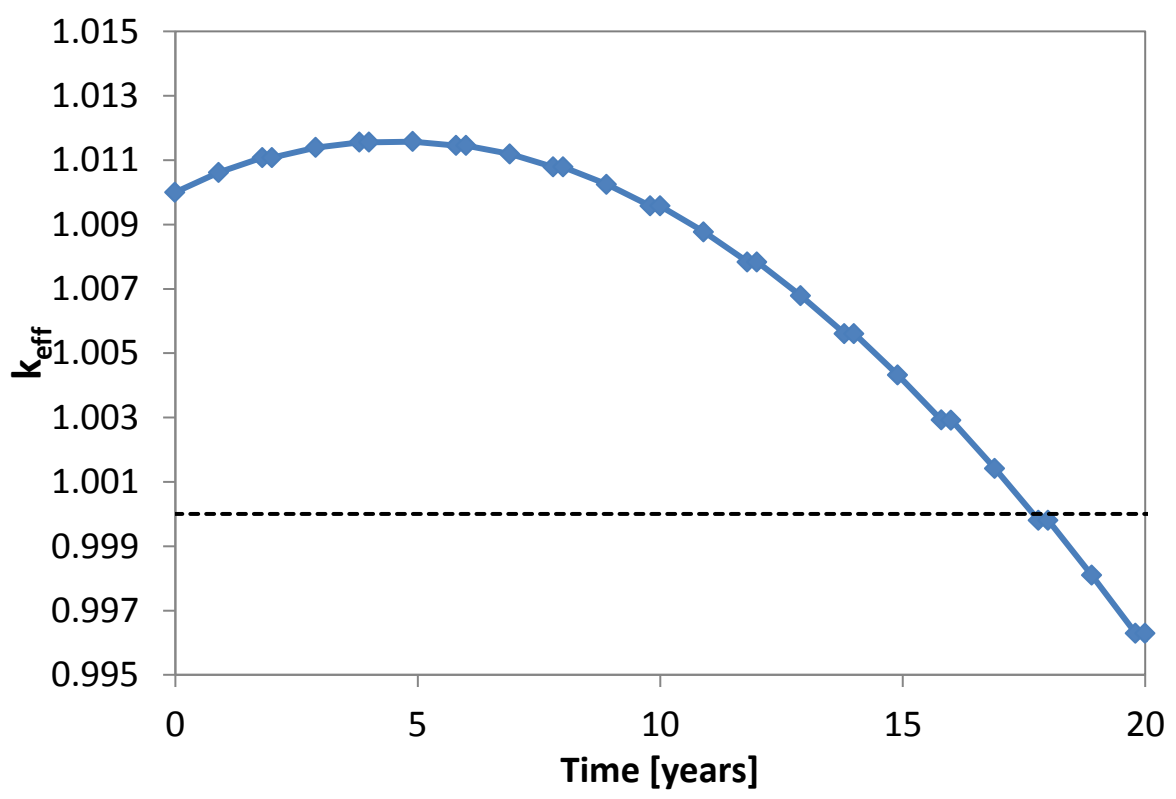

Figure 3.10 $\mathrm{k}_{\text {eff }}$ Evolution of the LEU/Th Fueled AFR-100 Core

Table 3.5 Core Performance Parameters of the LEU/Th fueled AFR-100 Core

\begin{tabular}{|l|r|}
\hline Characteristic & Value \\
\hline Thermal power, $\mathrm{MWt}$ & 250 \\
\hline Refueling interval, yr & 18 \\
\hline Number of batches & 1 \\
\hline Fuel form & LEU/Th layers \\
\hline LEU enrichment, $\%$ & 22.8 \\
\hline Initial heavy metal loading, $\mathrm{t}$ & 1.16 \\
\hline Burnup reactivity swing, $\% \Delta \mathrm{k}$ & 10.96 \\
\hline Specific power density, $\mathrm{MW} / \mathrm{t}$ & 58.3 \\
\hline Average power density, $\mathrm{W} / \mathrm{cm}^{3}$ & 123.1 \\
\hline Peak power density, W/cm & 1.35 \\
\hline Radial power peaking factor & 0.84 \\
\hline Overall fissile breeding ratio & $79.4 / 23.1$ \\
\hline Average discharge burnup in LEU/Th, GWd/t & $126.5 / 40.7$ \\
\hline Peak discharge burnup in LEU/Th, GWd/t & 3.47 \\
\hline Peak fast fluence, $10^{23} \mathrm{n} / \mathrm{cm}^{2}$ & \\
\hline
\end{tabular}

When the reactor is started, the core breeding ratio is only slightly smaller than unity. During operation, the radial power distribution is slightly shifting toward the core center, making the neutron leakage probability decrease and resulting in an increasing $k_{\text {eff }}$ value despite the lower than unity breeding ratio. As the fission products accumulate in the core, 
the conversion ratio becomes smaller and the $\mathrm{k}_{\text {eff }}$ value decreases. With no shuffling or refueling, the core remains critical for 18 years. The radial power distribution is provided at BOL and EOL in Figure 3.11.

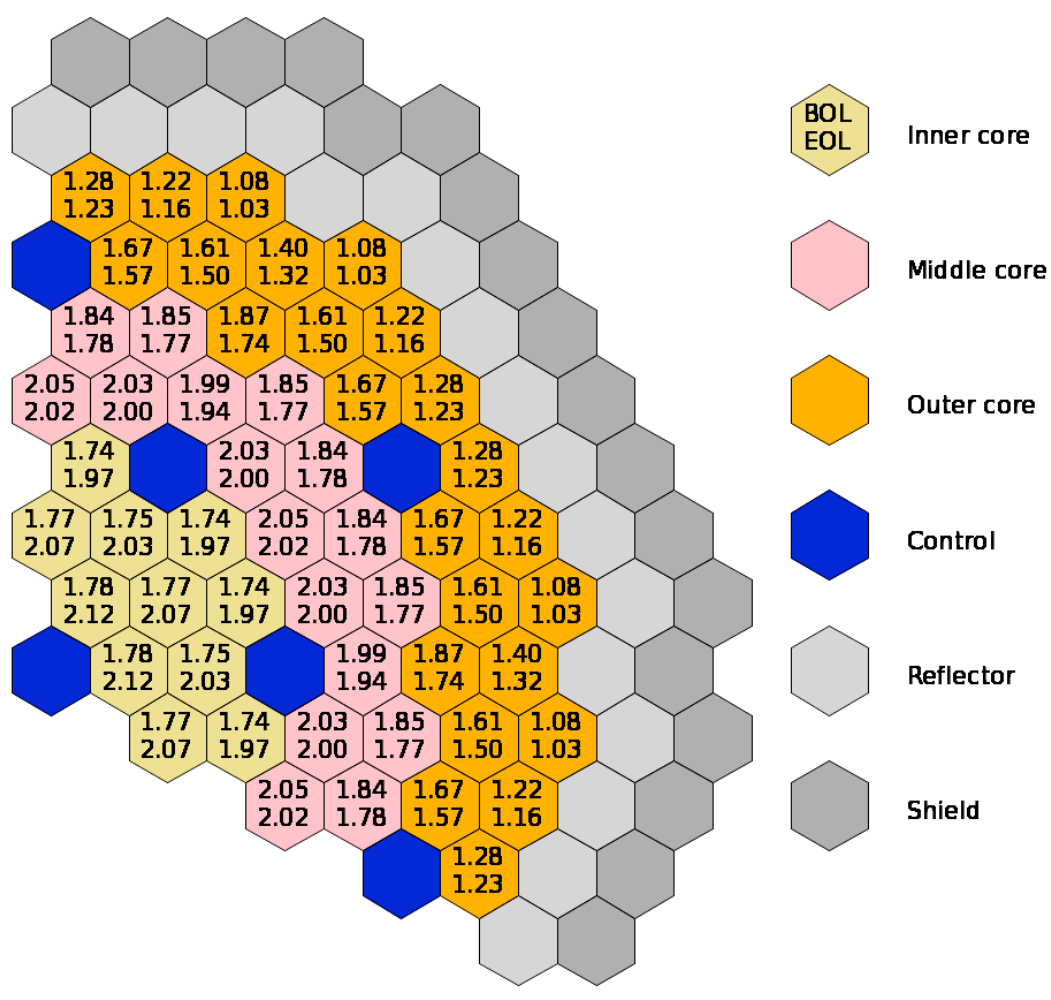

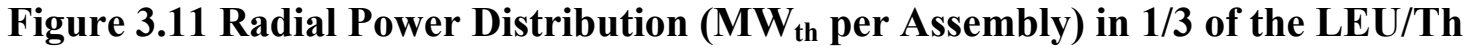 Fueled Core at BOL and EOL}

The average discharge burnup of the LEU fuel is $79.4 \mathrm{GWd} / \mathrm{t}$ and that of the thorium fuel is $23.1 \mathrm{GWd} / \mathrm{t}$. The LEU fuel discharge burnup is smaller than that obtained in the scenario discussed in Section 3.2 where Th-TRU fuel is used. Compared to the reference AFR-100 core where no thorium is used, the LEU fuel discharge burnup is approximately $21 \%$ smaller and the amount of energy produced per $\mathrm{kg}$ of ${ }^{235} \mathrm{U}$ is $\sim 40 \%$ smaller. The resulting peak fast fluence is $3.47 * 10^{23} \mathrm{n} / \mathrm{cm}^{2}$, which is smaller than the current irradiation experience with HT-9 cladding. The burnup reactivity swing is only $1.16 \% \Delta \mathrm{k}$ and the radial power peaking factor is 1.35 . These values are slightly smaller than those observed for the Th-TRU fueled AFR-100 core and for the reference AFR-100 design.

The heavy metal mass flow is provided in Table 3.6. After 18 years of operation, 1.5 tons of heavy metal have been consumed, which is equivalent to a burnup of $\sim 67 \mathrm{GWd} / \mathrm{t}$. About $1659 \mathrm{~kg}$ of uranium and $403 \mathrm{~kg}$ of thorium have been consumed by fission or converted by neutron absorption into TRU and ${ }^{233} \mathrm{U}$, which are in turn partially consumed in situ. The discharged fuel contains approximately $262 \mathrm{~kg}$ of ${ }^{233} \mathrm{U}, 2123 \mathrm{~kg}$ of ${ }^{235} \mathrm{U}$ and $513 \mathrm{~kg}$ of fissile plutonium. The required natural uranium and the separation work unit (SWU) to fill the initial core are 827 tons and 660 tons, respectively, with an assumed tail enrichment of $0.3 \%$. 
Table 3.6 Heavy Metal Mass Flow for the LEU/Th fueled AFR-100 Core

\begin{tabular}{|c|r|r|r|r|r|r|r|r|}
\cline { 2 - 9 } \multicolumn{1}{c|}{} & \multicolumn{4}{c|}{ Charge [kg] } & \multicolumn{4}{c|}{ Discharge [kg] } \\
\cline { 2 - 9 } \multicolumn{1}{c|}{} & Inner & Middle & Outer & Total & Inner & Middle & Outer & Total \\
\hline${ }^{232} \mathrm{Th}$ & 1600 & 1823 & 2170 & 5594 & 1455 & 1683 & 2052 & 5190 \\
\hline${ }^{233} \mathrm{U}$ & - & - & - & - & 87 & 90 & 85 & 262 \\
\hline${ }^{234} \mathrm{U}$ & - & - & - & - & 4 & 3 & 2 & 10 \\
\hline${ }^{235} \mathrm{U}$ & 574 & 1094 & 1776 & 3443 & 298 & 614 & 1211 & 2123 \\
\hline${ }^{236} \mathrm{U}$ & - & - & - & - & 48 & 83 & 102 & 232 \\
\hline${ }^{238} \mathrm{U}$ & 2294 & 4376 & 7104 & 13774 & 2109 & 4061 & 6761 & 12931 \\
\hline${ }^{238} \mathrm{Pu}$ & - & - & - & - & 1 & 1 & 0 & 2 \\
\hline${ }^{239} \mathrm{Pu}$ & - & - & - & - & 107 & 184 & 222 & 513 \\
\hline${ }^{240} \mathrm{Pu}$ & - & - & - & - & 5 & 7 & 6 & 19 \\
\hline${ }^{241} \mathrm{Pu}$ & - & - & - & - & 0.2 & 0.2 & 0.1 & 0.5 \\
\hline${ }^{242} \mathrm{Pu}$ & - & - & - & - & $\sim 0$ & $\sim 0$ & $\sim 0$ & $\sim 0$ \\
\hline $\mathrm{MA}$ & - & - & - & - & 4 & 7 & 6 & 17 \\
\hline Total & 4468 & 7293 & 11050 & 22811 & 4118 & 6733 & 10449 & 21300 \\
\hline Fissile & 574 & 1094 & 1776 & 3443 & 492 & 888 & 1519 & 2898 \\
\hline
\end{tabular}




\section{Orifice Design and Steady-State Thermal-Hydraulic Performance}

Reactor orifice zoning and flow allocation were determined through steady-state thermal-hydraulic analysis using the sub-channel analysis code SE2-ANL. As shown in Figures 3.8 and 3.11, the change of the assembly-averaged power is notable in the scenarios studied because the burning region moves during irradiation. For the Th-TRU fueled AFR-100 core during transition, the maximum power increase is $+29.3 \%$, and it is $+19.1 \%$ for the LEU/Th fueled AFR-100 core.

The assembly orifice zoning and the flow rate allocation to the assemblies in each orifice zone were iteratively determined until all thermal-hydraulic design criteria were met. Generally, the flow rates were taken proportional to the heating rates in order to obtain uniform coolant outlet temperatures. The coolant inlet and bulk outlet temperatures were assumed to be $395^{\circ} \mathrm{C}$ and $550^{\circ} \mathrm{C}$, respectively. The average flow rate was determined such that the coolant temperature rise across the core is $155^{\circ} \mathrm{C}$.

\subsection{Th-TRU Fueled Core based on Progressive Fuel Conversion Scenario}

For the AFR-100 core where the initial LEU fuel assemblies are progressively replaced with Th-TRU fuel, the orificing and thermal hydraulic analysis is performed for the core during transition. The cycle where the first Th-TRU fuel assemblies are introduced in the AFR-100 core is the cycle where the maximum radial power peaking factor is occurring. The orificing and thermal hydraulic analyses are performed for this cycle. During the transition period it might be necessary to adapt the orificing strategy at each EOC to ensure an optimal cooling of the core. The purpose of this study being only to assess the feasibility of using thorium fuel in fast reactors, the orificing strategy is only determined for the cycle where the power peaking is occurring.

The fuel assemblies are grouped into nine orifice zones, while the non-fueled assemblies are grouped into four orifice zones. Figures 4.1 and 4.2 show the orifice zones and coolant flow rates in each assembly, respectively. The coolant flow rate and velocity are small because of the low power density, compared to conventional fast reactors. Due to the slow coolant velocity and shorter fuel pin, the average pressure drop is typically less than 10 psi in the AFR-100 core concept. 


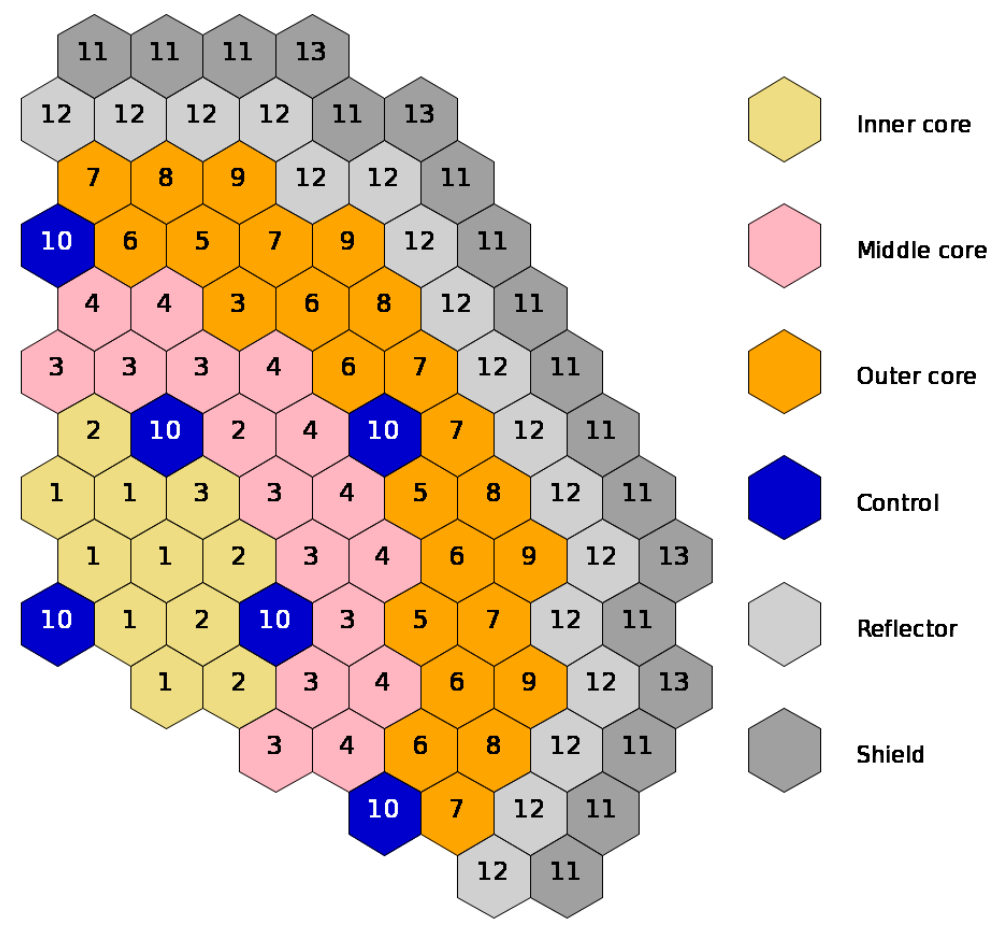

Figure 4.1 Orifice Zones for the Th-TRU Fueled Core

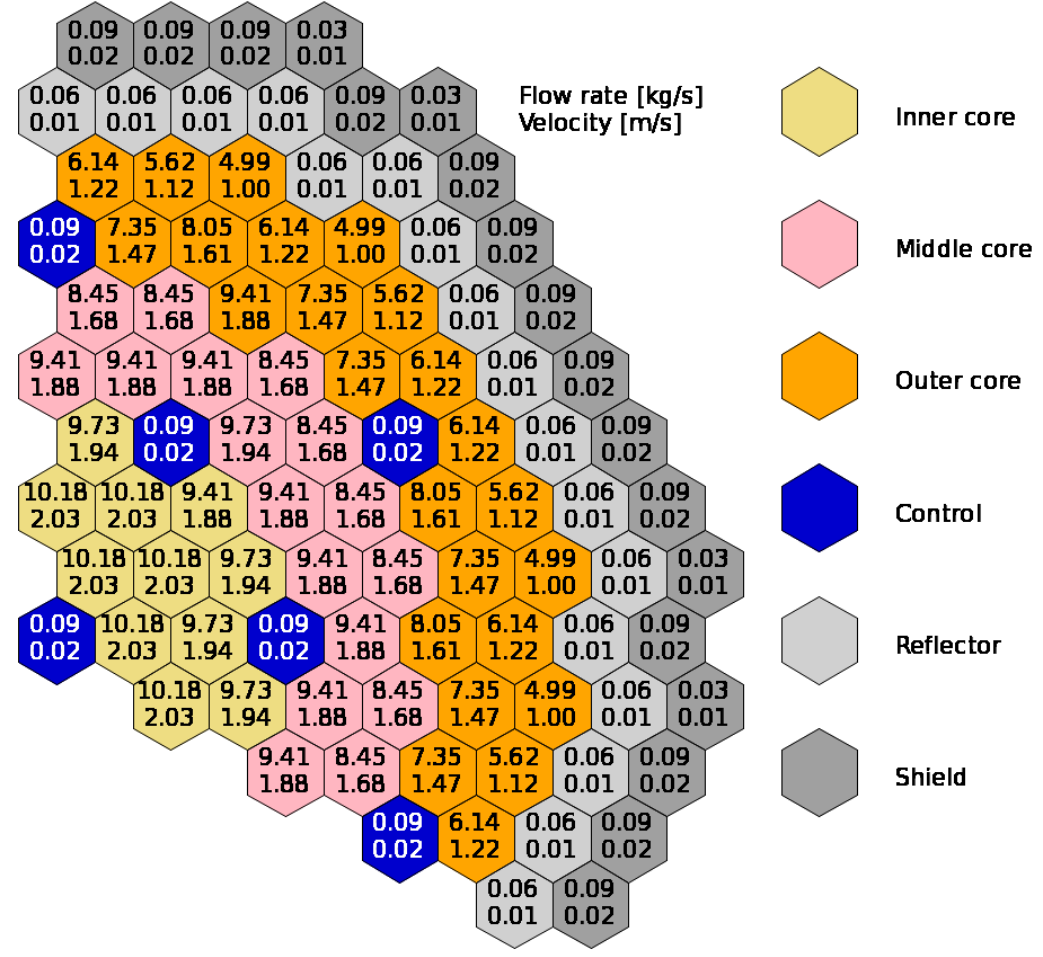

Figure 4.2 Coolant Flow Rate and Velocity for the Th-TRU Fueled Core 
Figure 4.3 shows the peak cladding inner wall temperatures with $2 \sigma$ hot channel factors that were employed in the CRBR core design [18]. The maximum peak $2 \sigma$ cladding inner wall temperature occurs at BOC in a LEU fuel assemblies located in the outer core region. The power distribution shifting toward the core center during the cycle, the peak $2 \sigma$ cladding inner wall temperature is decreasing in the outer core region and is increasing in the inner core region. The overall peak $2 \sigma$ cladding inner wall temperature is $681^{\circ} \mathrm{C}$, which is lower than the target fuel-cladding eutectic temperature for advanced metal fuel $\left(700^{\circ} \mathrm{C}\right)$. Due to the little data available regarding thorium-based metal fuel, especially with respect to the fission product migration which limits the fuel-cladding eutectic temperature, the same eutectic temperature as for metallic uranium fuel is used throughout the core.

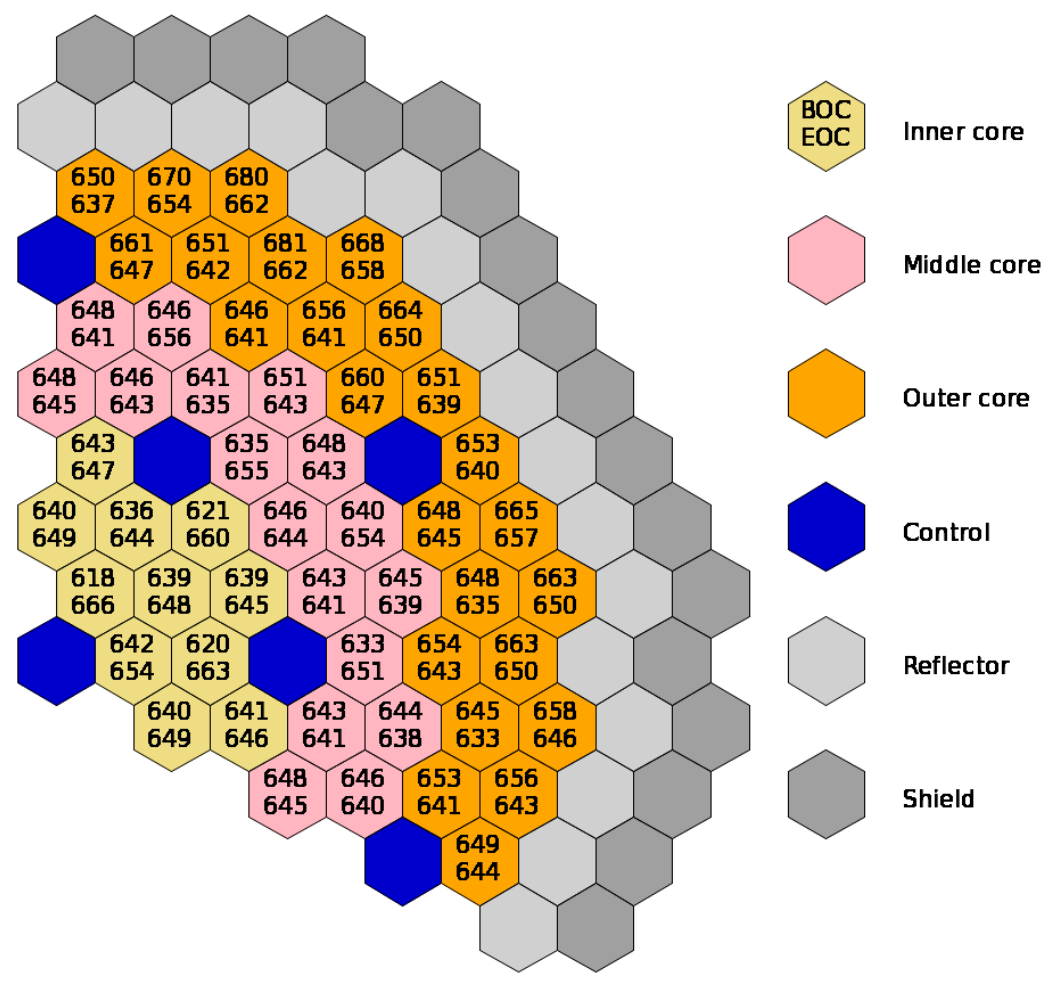

Figure 4.3 Peak 2 $\sigma$ Cladding Inner Wall Temperatures $\left({ }^{\circ} \mathrm{C}\right)$ for the Th-TRU Fueled Core

The overall peak fuel temperature is $766^{\circ} \mathrm{C}$ and is occurring at EOC in the Th-TRU assembly loaded the nearest from the core center. No data is available regarding the melting temperature of Th-TRU, so the same melting temperature as for $\mathrm{U}-\mathrm{Zr}, 1200^{\circ} \mathrm{C}$, is assumed. This assumption appears to be conservative since the thorium based fuels have typically a larger melting temperature than the equivalent uranium based fuel [19]. The overall minimum margin to fuel melt is about $434^{\circ} \mathrm{C}$, which is much higher than that of a typical fast reactor due to the derated power density.

The mixed average coolant outlet temperatures of individual assemblies are shown in Figure 4.4. The coolant outlet temperatures of the outer core assemblies are higher than 
those of the inner core assemblies at BOC, but the trend becomes reversed at EOC because of the propagation of the burning zone. In order to reduce the thermal stress of the upper internal structure due to the coolant temperature gradient, the flow rate of each assembly was controlled such that the coolant outlet temperature from an assembly does not differ by more than $50^{\circ} \mathrm{C}$ compared to the average temperature of surrounding assemblies.

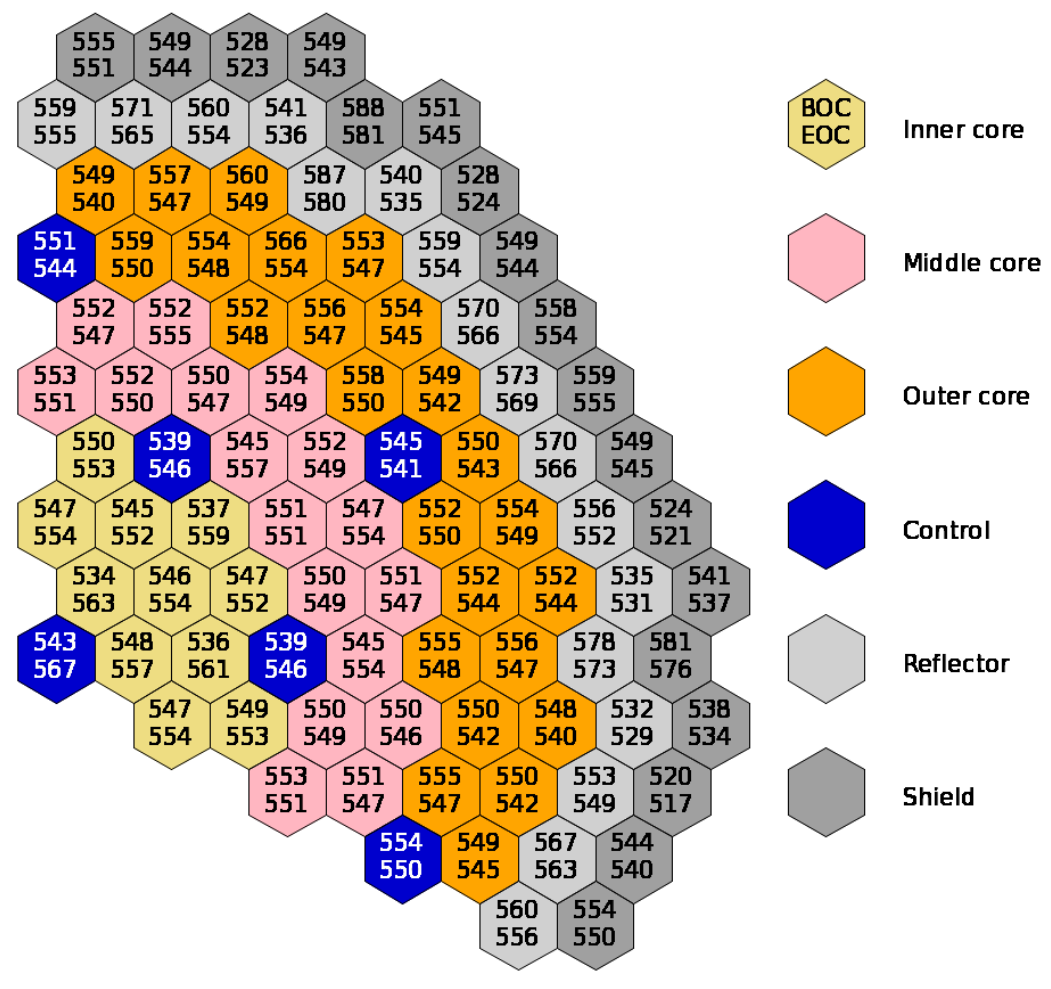

Figure 4.4 Mixed Mean Coolant Output Temperatures $\left({ }^{\circ} \mathrm{C}\right)$ for the Th-TRU Fueled Core

\subsection{LEU/Th Fueled Core based on Whole Core Fuel Conversion Scenario}

The orificing and thermal hydraulics analysis is performed for the AFR-100 core being fueled with fuel assemblies made of several layers of LEU and thorium. For this scenario, the maximum power variation between BOC and EOC is $+19 \%$ and occurs in the assemblies located near the core center. Since no refueling and no shuffling occur, the same orificing strategy is valid for the entire core lifetime.

The fuel assemblies are grouped into eight orifice zones, while the non-fuel assemblies are grouped into four orifice zones. Figures 4.5 and 4.6 show the orifice zone and assembly flow rates, respectively. 


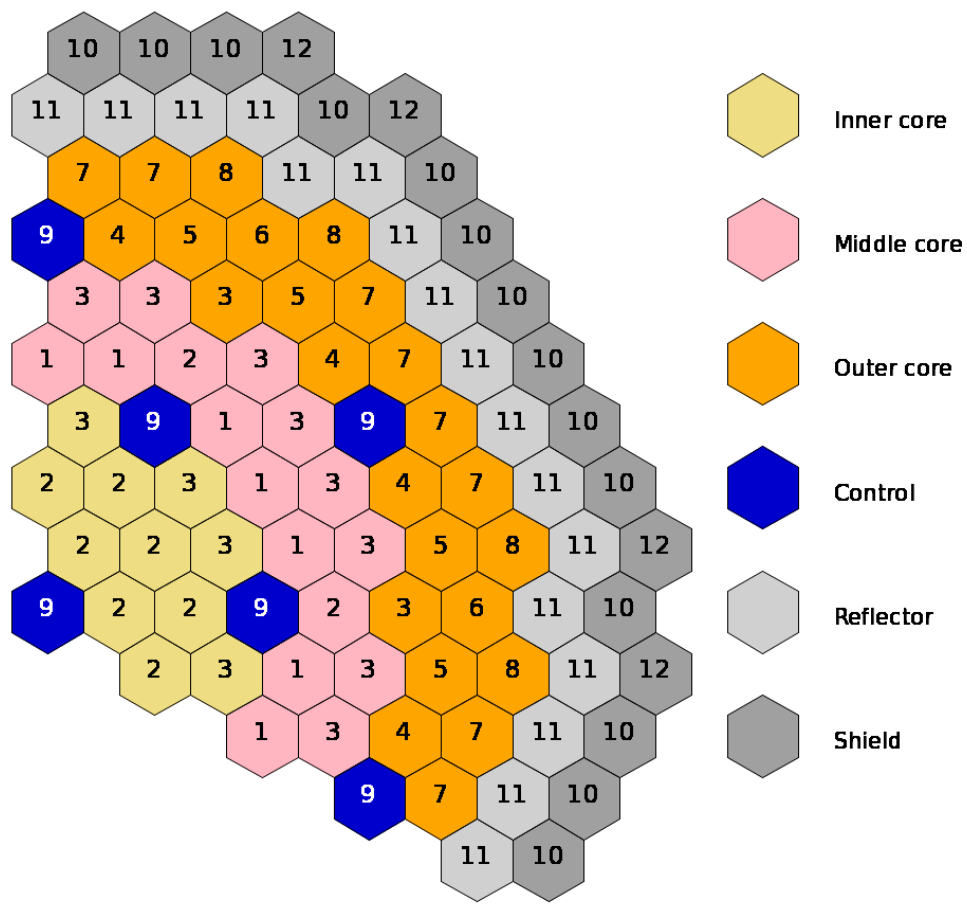

Figure 4.5 Orifice Zones for the LEU/Th Fueled Core

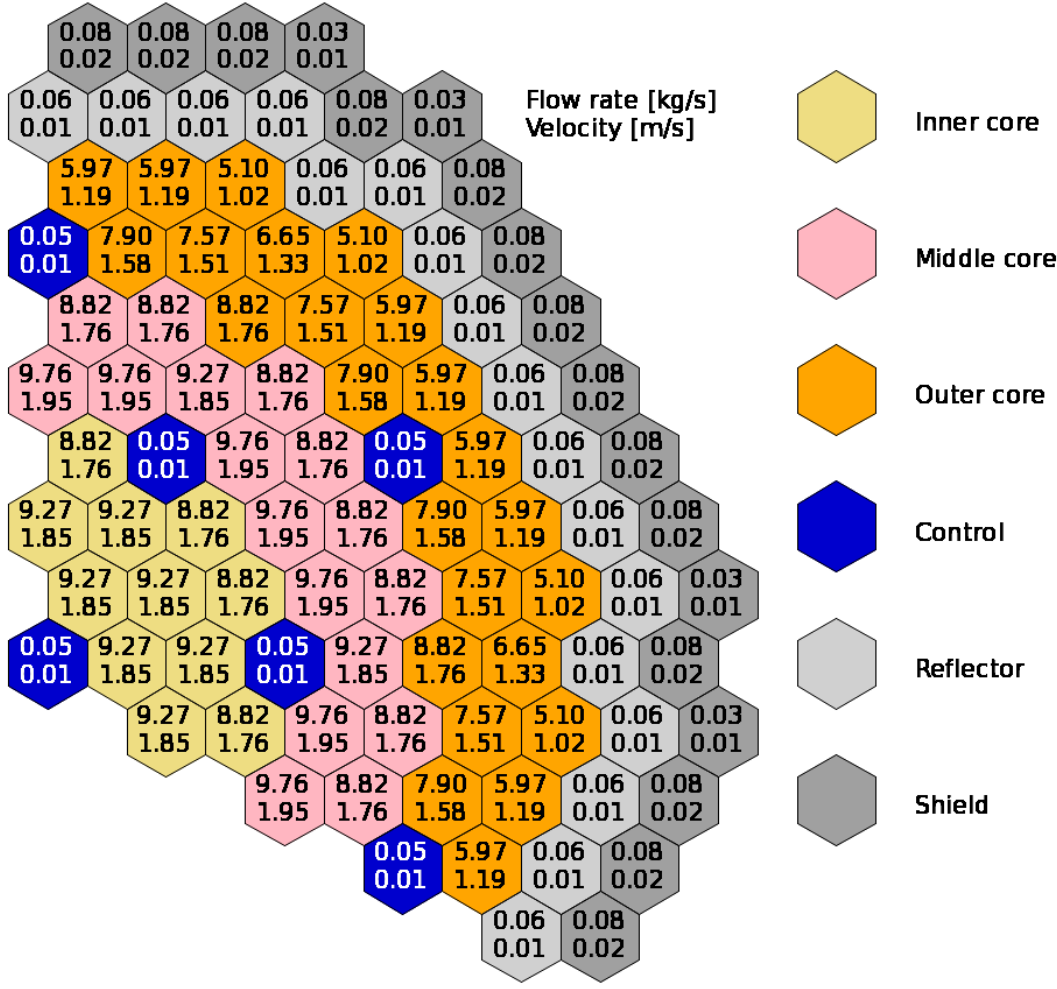

Figure 4.6 Coolant Flow Rate and Velocity for the LEU/Th Fueled Core 
The peak $2 \sigma$ cladding inner wall temperatures are shown for each assembly at BOL and EOL in Figure 4.7. The maximum peak temperature is $669^{\circ} \mathrm{C}$ and occurs at BOL in several of the fuel assemblies loaded in the outer core region. As the power distribution moves toward the core center during the cycle, the peak $2 \sigma$ cladding inner wall temperature is decreasing in the outer core region and is increasing in the inner core region. At EOL the maximum peak temperature occurs in the innermost assemblies and is $667^{\circ} \mathrm{C}$. During the entire cycle the peak $2 \sigma$ cladding inner wall temperatures remain comfortably below the fuel-cladding eutectic temperature of advanced metal fuel.

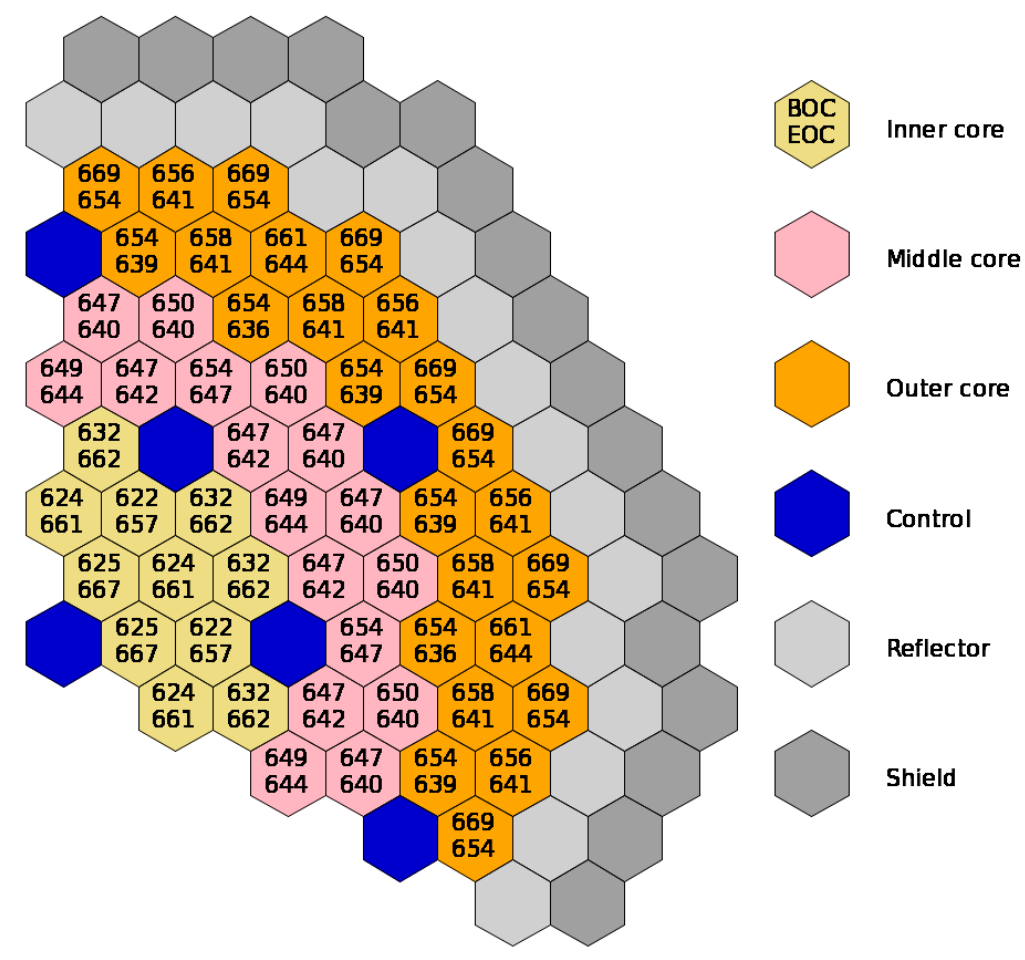

\section{Figure 4.7 Peak 2 $\sigma$ Cladding Inner Wall Temperatures $\left({ }^{\circ} \mathrm{C}\right)$ for the LEU/Th Fueled Core}

The overall peak fuel temperature for this scenario, $699^{\circ} \mathrm{C}$, occurs at EOL in several fuel assemblies located near the core center. It is smaller than in the previous scenario because of the smaller maximum power generated by a single assembly. It is also smaller than for the reference AFR-100 core for the same reason. The overall minimum margin to fuel melt is a comfortable $500^{\circ} \mathrm{C}$.

The mixed average coolant outlet temperature of the individual core assemblies are shown in Figure 4.8. The coolant outlet temperatures of the outer core assemblies are higher than those of the inner core assemblies at BOL, but the trend becomes reversed at EOL because of the propagation of the burning zone. In this scenario the coolant outlet temperature from an assembly does not differ by more than $50^{\circ} \mathrm{C}$ compared to the average temperature of surrounding assemblies. 


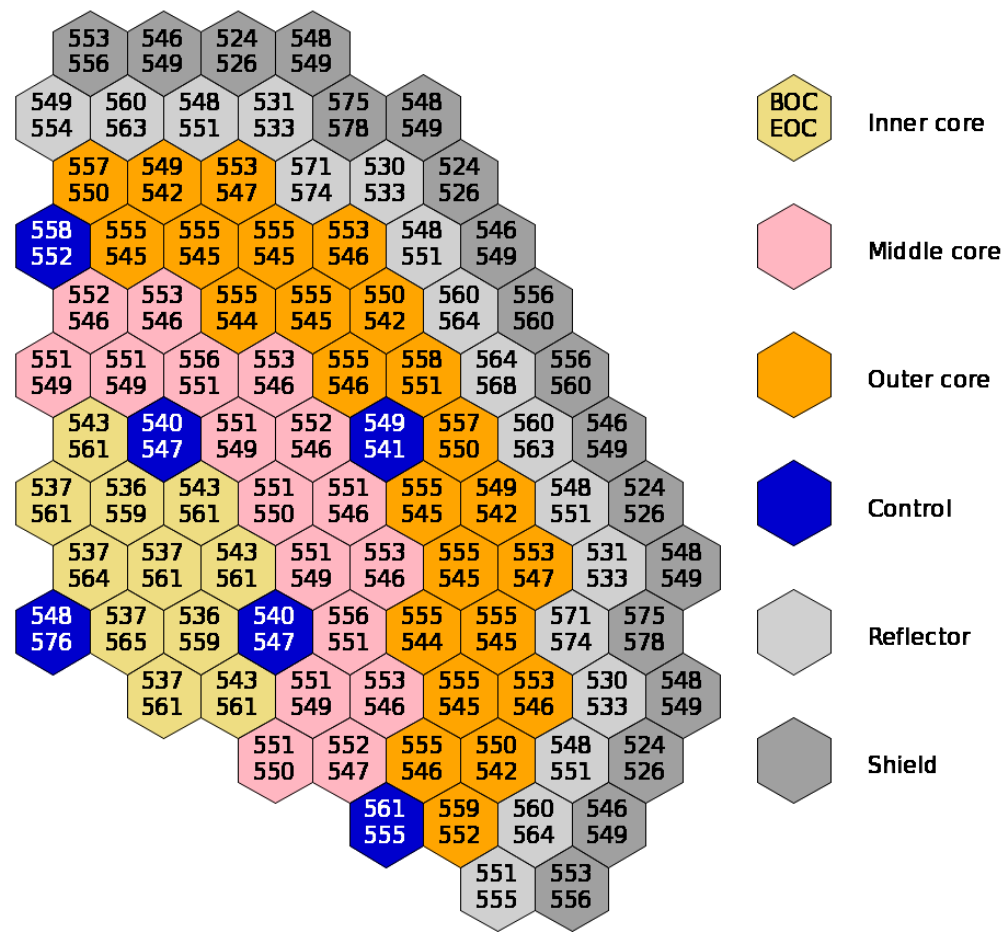

Figure 4.8 Mixed Mean Coolant Output Temperatures $\left({ }^{\circ} \mathrm{C}\right)$ for the LEU/Th Fueled Core 


\section{Kinetic Parameters and Reactivity Feedback Coefficients}

The reactor kinetics parameters and reactivity coefficients were evaluated using the VARI3D and DIF3D codes. The irradiation induced swelling of the metal fuel and thermal expansion were modeled by a uniform axial growth of $8 \%$ and the bond sodium was replaced into the above fuel slug for all the calculations. Therefore, the axial thermal expansion is governed by the thermal expansion of the cladding material (because the fuel is contacting the cladding) during the entire study.

In order to measure the capacity of the AFR-100 cores studied to attain inherent safety responses to Anticipated Transients without Scram (ATWS), the integral reactivity parameters $(A, B$, and $C)$ of the quasi-static reactivity balance analysis were calculated. In these calculations, the average coolant temperature rise across the core $\left(\Delta \mathrm{T}_{\mathrm{c}}\right)$ was $155^{\circ} \mathrm{C}$, with an average inlet and outlet coolant temperatures of $395^{\circ} \mathrm{C}$ and $550^{\circ} \mathrm{C}$, respectively.

For acceptable asymptotic core outlet temperatures for possible unprotected accident scenarios such as Loss of Heat Sink (ULOHS), Transient Over-Power (UTOP), Loss of Flow (ULOF), chilled inlet, and pump over-speed, the integral reactivity parameters A, $\mathrm{B}$, and $\mathrm{C}$ should satisfy the following three necessary conditions:

$$
\begin{gathered}
\mathrm{A} / \mathrm{B}<1, \\
1<\mathrm{C} \cdot \Delta \mathrm{T}_{\mathrm{c}} / \mathrm{B}<2, \\
\Delta \rho_{T O P} /|\mathrm{B}|<1
\end{gathered}
$$

The integral parameter " $\mathrm{A}$ " is the reactivity decrement due to the fuel temperature rise from the coolant average temperature to the fuel average temperature. The integral parameter "B" represents the reactivity decrement experienced when the coolant and fuel temperature rise from the zero power isothermal condition at coolant inlet temperature to the coolant average temperature. The inlet temperature coefficient " $\mathrm{C}$ " is the sum of the Doppler, fuel axial expansion, sodium density, and radial expansion coefficients. The transient overpower initiator $\left(\Delta \rho_{\mathrm{TOP}}\right)$ was calculated using the number of control assemblies of the primary control system (10) and a first rod out interaction factor of 1.15 . A thorough analysis of the reactivity control system for the scenarios envisioned would be required in order to determine the correct value.

\subsection{Th-TRU Fueled Core based on Progressive Fuel Conversion Scenario}

For the AFR-100 core where the initial LEU fuel is progressively replaced with ThTRU fuel, the calculated reactor reactivity feedback coefficients are presented in Table 5.1 at the $\mathrm{BOC}$ and $\mathrm{EOC}$ of the two first cycles following the first fuel replacement and at the BOC and EOC of the equilibrium cycle. The reactivity coefficients for the initial 24 years cycle are the same as those of the reference AFR-100 design [1] and are not provided here. Figures 5.1 and 5.2 show the evolution of the sodium void worth, Doppler coefficient and axial and radial expansion coefficients for the transition period until equilibrium is reached. 
Table 5.1 Kinetics Parameters and Reactivity Feedback Coefficient for the Th-TRU fueled Core

\begin{tabular}{|c|r|r|r|r|r|r|}
\cline { 2 - 7 } \multicolumn{1}{c|}{} & \multicolumn{2}{c|}{ Transition cycle 1 } & \multicolumn{2}{c|}{ Transition cycle 2} & \multicolumn{2}{c|}{ Equilibrium } \\
\cline { 2 - 7 } \multicolumn{1}{c|}{} & \multicolumn{1}{c|}{ BOC } & \multicolumn{1}{c|}{ EOC } & \multicolumn{1}{c|}{ BOC } & EOC & BOC & EOC \\
\hline $\begin{array}{c}\text { Effective delayed neutron } \\
\text { fraction }\left(\beta_{\text {eff }}\right)\end{array}$ & 0.0045 & 0.0042 & 0.0038 & 0.0037 & 0.0029 & 0.0029 \\
\hline $\begin{array}{c}\text { Radial expansion } \\
\text { coefficient, } \phi /{ }^{\circ} \mathrm{C}\end{array}$ & -0.16 & -0.18 & -0.20 & -0.21 & -0.28 & -0.27 \\
\hline $\begin{array}{c}\text { Axial expansion } \\
\text { coefficient }, \phi /{ }^{\circ} \mathrm{C}\end{array}$ & -0.05 & -0.06 & -0.07 & -0.07 & -0.09 & -0.09 \\
\hline Sodium void worth,$\$$ & 2.57 & 2.97 & 3.48 & 3.61 & 4.71 & 4.24 \\
\hline $\begin{array}{c}\text { Sodium density } \\
\text { coefficient }, \phi /{ }^{\circ} \mathrm{C}\end{array}$ & 0.08 & 0.10 & 0.11 & 0.12 & 0.15 & 0.14 \\
\hline Doppler coefficient, $\phi /{ }^{\circ} \mathrm{C}$ & -0.07 & -0.07 & -0.07 & -0.07 & -0.07 & -0.06 \\
\hline
\end{tabular}

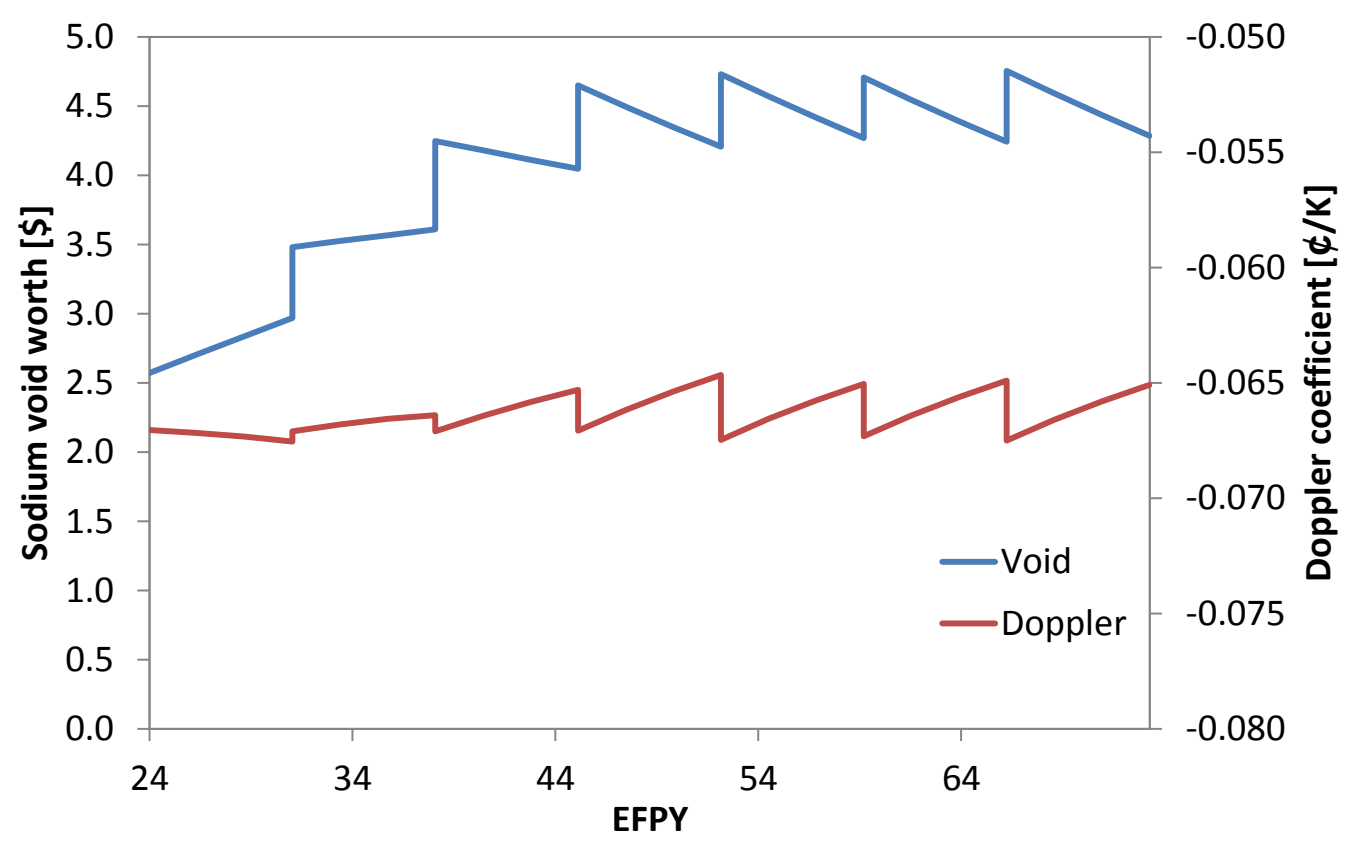

Figure 5.1 Sodium Void Worth and Doppler Coefficient Evolution for the Th-TRU Fueled Core 


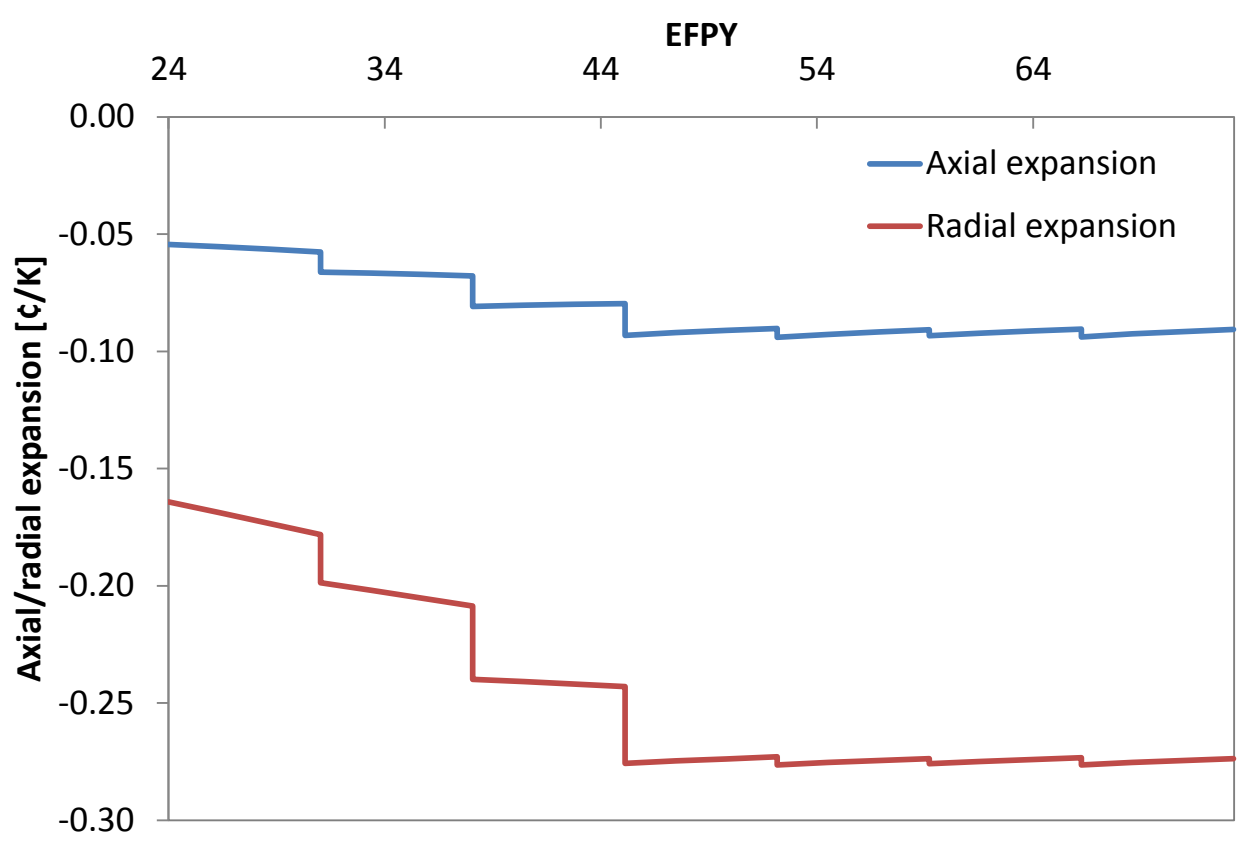

Figure 5.2 Axial and Radial Expansion Coefficients Evolution for the Th-TRU Fueled Core

At the beginning of the transition period, the effective delayed neutron fraction is approximately $450 \mathrm{pcm}$ and corresponds to that of a mixture of uranium and plutonium metal fuel. As the LEU fuel assemblies are replaced with Th-TRU fuel assemblies, the effective delayed neutron fraction decreases and reaches about $290 \mathrm{pcm}$ for the core at equilibrium. Within the transition cycles the delayed neutron fraction is decreasing as ${ }^{235} \mathrm{U}$ is consumed and ${ }^{239} \mathrm{Pu}$ bred. At equilibrium no change is observed within a cycle because the effective delayed neutron fraction of ${ }^{233} \mathrm{U}$ and ${ }^{239} \mathrm{Pu}$ are similar.

During the transition period, it is observed that the sodium void worth is increasing within a cycle as well as a result of replacing LEU fuel assemblies with Th-TRU fuel assemblies. This is due to the increasing concentration of ${ }^{239} \mathrm{Pu}$ in the core, having a reproduction factor increasing more with spectrum hardening than ${ }^{235} \mathrm{U}$. During the equilibrium cycles ${ }^{239} \mathrm{Pu}$ is consumed and ${ }^{233} \mathrm{U}$ is bred, slightly decreasing the sodium void worth. The sodium void worth is always positive and reaches its maximum, $\$ 4.71$, at equilibrium because of the small effective delayed neutron fraction. This value is $56 \%$ larger than for the reference AFR-100 core fueled with LEU only.

The Doppler coefficient remains approximately constant during the transition cycles and at equilibrium because the positive reactivity change resulting from the increasing amount of ${ }^{239} \mathrm{Pu}$ during the transition is offset by the decreasing effective delayed neutron fraction. The axial and radial expansion coefficients, which depend mostly on geometry and power distribution, follow an evolution inverse to that of the effective delayed neutron fraction. They are getting more negative during the transition period and remain approximately constant at equilibrium. 
The results of the quasi-static reactivity balance analysis are provided in Table 5.2 at $\mathrm{BOC}$ and EOC for the two cycles following the first fuel replacement and at BOC and EOC of the equilibrium cycle. The values reported in this table indicate that the Th-TRU fueled AFR-100 core has overall favorable inherent safety features. However, when the analysis is performed for every transition cycle, it is found that at the beginning of the fourth transition cycle, the $\Delta \rho_{T O P} /|\mathrm{B}|<1$ condition is not met because of the somewhat high $\mathrm{k}_{\mathrm{eff}}$ value (Figure 3.6). Although the excess reactivity of this cycle is smaller than that observed during the initial 24 years cycle, the larger sodium void worth resulting from decreasing $\beta_{\text {eff }}$ values makes the $\Delta \rho_{T O P} /|\mathrm{B}|$ ratio larger than unity. A solution to this problem would be to use a different loading pattern and/or fuel enrichment for this cycle in order to decrease the $\mathrm{k}_{\mathrm{eff}}$ value at BOC.

Table 5.2 Integral Reactivity Parameters for Quasi-Static Reactivity Balance for the Th-TRU Fueled Core

\begin{tabular}{|c|c|c|c|c|c|c|}
\hline & \\
\hline & \multicolumn{2}{|c|}{ Transition cycle 1} & \multicolumn{2}{|c|}{ Transition cycle 2} & \multicolumn{2}{|c|}{ Equilibrium } \\
\hline & $\mathrm{BOC}$ & $\mathrm{EOC}$ & $\mathrm{BOC}$ & $\mathrm{EOC}$ & $\mathrm{BOC}$ & EOC \\
\hline A, power coefficient, $\phi$ & -6.0 & -6.1 & -6.0 & -6.0 & -6.1 & -5.9 \\
\hline B, power/flow coefficient, $\varnothing$ & -28.4 & -29.9 & -32.4 & -33.7 & -43.4 & -43.8 \\
\hline $\begin{array}{l}\mathrm{C} \text {, inlet temperature coefficient, } \\
\phi /{ }^{\circ} \mathrm{C}\end{array}$ & -0.20 & -0.21 & -0.22 & -0.23 & -0.28 & -0.29 \\
\hline $\begin{array}{l}\Delta \rho_{\mathrm{TOP}}, \text { transient over power } \\
\text { initiator, } \varnothing\end{array}$ & 22 & 14 & 19 & 3 & 34 & 3 \\
\hline \multicolumn{7}{|c|}{ Sufficient conditions to have favorable inherent safety features } \\
\hline $\mathrm{A} / \mathrm{B}<1$ & 0.21 & 0.20 & 0.19 & 0.18 & 0.14 & 0.13 \\
\hline $1<\mathrm{C} \Delta \mathrm{T}_{\mathrm{c}} / \mathrm{B}<2$ & 1.10 & 1.08 & 1.05 & 1.04 & 1.01 & 1.03 \\
\hline$\Delta \rho_{\mathrm{TOP}} /|\mathrm{B}|<1$ & 0.77 & 0.46 & 0.59 & 0.09 & 0.78 & 0.07 \\
\hline
\end{tabular}

\subsection{LEU/Th Fueled Core based on Whole Core Fuel Conversion Scenario}

The reactor reactivity feedback coefficients calculated for the AFR-100 being loaded with LEU/Th layered fuel assemblies are presented in Table 5.3 at the BOL, middle-oflife (MOL) and EOL.

Table 5.3 Kinetics Parameters and Reactivity Feedback Coefficient for the LEU/Th Fueled Core

\begin{tabular}{|l|r|r|r|}
\cline { 2 - 4 } \multicolumn{1}{c|}{} & \multicolumn{1}{c|}{ BOL } & \multicolumn{1}{c|}{ MOL } & \multicolumn{1}{c|}{ EOL } \\
\hline Effective delayed neutron fraction $\left(\beta_{\text {eff }}\right)$ & 0.0071 & 0.0063 & 0.0056 \\
\hline Radial expansion coefficient, $\phi /{ }^{\circ} \mathrm{C}$ & -0.11 & -0.12 & -0.14 \\
\hline Axial expansion coefficient, $\phi /{ }^{\circ} \mathrm{C}$ & -0.03 & -0.04 & -0.04 \\
\hline Sodium void worth, $\$$ & -0.14 & 0.18 & 0.55 \\
\hline Sodium density coefficient, $\phi /{ }^{\circ} \mathrm{C}$ & $\sim-0.01$ & 0.01 & 0.02 \\
\hline Doppler coefficient, $\phi /{ }^{\circ} \mathrm{C}$ & -0.03 & -0.03 & -0.03 \\
\hline
\end{tabular}


All the reactivity coefficients vary almost linearly during the cycle. With the exception of the sodium void worth reactivity coefficient, the reactivity coefficients variation is mostly due to the change in the effective delayed neutron fraction. At BOL the delayed neutron fraction corresponds to that of LEU fuel. $\mathrm{As}^{239} \mathrm{Pu}$ and ${ }^{233} \mathrm{U}$ are bred, the delayed neutron fraction decreases. At BOL the sodium void worth is slightly negative because of the large reactor neutron leakage probability and use of thorium fuel. As the ${ }^{239} \mathrm{Pu}$ concentration increases and the radial power distribution shifts toward the core center, decreasing the neutron leakage probability, the sodium void worth increases. At EOL it is $\$ 0.55$, which is significantly smaller than the sodium void worth of the ThTRU fueled AFR-100 core and of the reference AFR-100 core.

The results of the quasi-static reactivity balance analysis are provided in Table 5.4. These results indicate that the LEU/Th fueled AFR-100 has favorable inherent safety features. All the necessary conditions are met with comfortable margins, in particular due to the small sodium void worth. However, since only the necessary conditions were tested using the integral reactivity parameters, explicit dynamic modeling of ATWS transients will be required in the future.

Table 5.4 Integral Reactivity Parameters for Quasi-Static Reactivity Balance for the LEU/Th fueled AFR-100 Core

\begin{tabular}{|l|r|r|r|}
\cline { 2 - 4 } \multicolumn{1}{c|}{} & BOL & MOL & EOL \\
\hline A, power coefficient, $\phi$ & -2.5 & -2.7 & -2.9 \\
\hline B, power/flow coefficient, $\phi$ & -21.7 & -23.9 & -25.8 \\
\hline $\mathrm{C}$, inlet temperature coefficient, $\phi /{ }^{\circ} \mathrm{C}$ & -0.17 & -0.19 & -0.20 \\
\hline$\Delta \rho_{\mathrm{TOP}}$, transient over power initiator, $\phi$ & 9 & 14 & 0 \\
\hline Sufficient conditions to have favorable inherent safety features \\
\hline $\mathrm{A} / \mathrm{B}<1$ & 0.12 & 0.11 & 0.11 \\
\hline $1<\mathrm{C} \Delta \mathrm{T}_{\mathrm{c}} / \mathrm{B}<2$ & 1.24 & 1.20 & 1.17 \\
\hline$\Delta \rho_{\mathrm{TOP}} /|\mathrm{B}|<1$ & 0.43 & 0.57 & 0.00 \\
\hline
\end{tabular}




\section{Conclusion}

The feasibility of fuel conversion from uranium to thorium in a fast reactor was assessed along with the impact on the reactor performance. The study was performed for a small size fast reactor core, the AFR-100, which is targeting the emerging electricity markets where a more conventional, larger, fast reactor is not a viable option. In addition to the neutronics performance, the thermal hydraulics and inherent safety performance of the AFR-100 core fueled with thorium fuel have been assessed.

Three main approaches were envisioned in order to load thorium-based metal fuel in the AFR-100 core. The first approach is a progressive fuel conversion without fissile support. It consists in progressively replacing the burnt uranium-based fuel with pure thorium-based fuel without fissile material addition. It was found that in order to obtain a critical core configuration after the first replacement, no more than nine uranium-based fuel assemblies can be replaced with thorium-based fuel. However, this is impractical as the resulting core can only remain critical for about four years resulting in a low fuel discharge burnup and no additional fuel replacement is possible.

The second approach consists of operating the reference AFR-100 core for 24 years and then replacing one out of four fuel batches every 7.04 years with thorium-based fuel mixed with TRU. The TRU mass fraction required at equilibrium is the same as that required during the transition cycle, $18.6 \%$. The original uranium-based fuel is discharged with an average burnup of $120 \mathrm{GWd} / \mathrm{t}$ and the thorium-based fuel with an average burnup of $101 \mathrm{GWd} / \mathrm{t}$ at equilibrium. The thermal hydraulic and preliminary inherent safety performances of this core were found satisfactory and similar to those of the reference AFR-100 core.

The last approach proposed consists in replacing all the original uranium-based fuel assemblies at once with assemblies made of several layers of LEU and pure thorium. The mode of operation is a one-batch mode, similarly to the reference AFR-100 mode of operation. When the thorium loaded at BOL accounts for $25 \%$ of the total heavy metal mass, the core remains critical for 18 years without refueling or shuffling. The average LEU and thorium discharge burnups are $79 \mathrm{GWd} / \mathrm{t}$ and $23 \mathrm{GWd} / \mathrm{t}$, respectively. The thermal-hydraulic performance of this core was found satisfactory and the preliminary inherent safety performance of this core was found to exceed that of the reference AFR100 because of the significantly smaller coolant void worth.

Although those results were obtained for a small size fast reactor core the overall conclusions are expected to be also valid for a more conventional fast reactor design, which is a large size core with a high specific power density. Despite the better neutron economy resulting for a larger core, transition to a self-sustaining cycle requiring only pure thorium fuel (i.e., progressive fuel conversion without fissile support or breed-andburn mode operation without fuel reprocessing) will remain impractical. However, for reactor concepts in which fuel is being reprocessed, it is possible to design a thorium fueled fast breeder reactor as shown in the INFCE study [20]. The second and third approaches (i.e., progressive or whole core fuel conversion with fissile support) would still be viable options for a conventional fast reactor core. For those approaches, higher thorium fuel discharge burnup and lower required fissile support than with the AFR-100 core are expected. In particular, the third approach might be possible in a heterogeneous 
core concept in which LEU and thorium are loaded in separate assemblies instead of LEU/thorium layered fuel assemblies. In this case fuel shuffling is required to achieve a desired thermal-hydraulic performance. The conclusions regarding the thermal-hydraulic performance and inherent safety features are not expected to change.

The lack of reliable data regarding the physical properties and irradiation behavior of thorium-based metal fuel is a major hindrance toward the development of reactor concepts relying on use of thorium-based fuels. Little or no data could be found regarding Th-TRU fuel characteristic, the impact of fission product accumulation on thorium metal fuel properties, the fuel-cladding chemical interactions as well as the fuel irradiation behavior. In addition, computer codes and databases used to perform this study would need to be thoroughly updated in order to make them fully functional with thorium-based fuels. 


\section{References}

1. T. K. Kim, C. Grandy, and R. N. Hill, "A 100MWe Advanced Sodium-Cooled Fast Reactor Core Concept," PHYSOR 2012 - Advances in Reactor Physics, Knoxville, Tennessee, USA, April 15-20, 2012

2. K. L. Derstine, "DIF3D: A Code to Solve One-, Two-, and Three-Dimensional Finite Difference Diffusion Theory Problems," ANL-82-64, Argonne National Laboratory (1984).

3. B. J. Toppel, "A User's Guide to the REBUS-3 Fuel Cycle Analysis Capability," ANL-83-2, Argonne National Laboratory (1983).

4. "NSEC No. 350 ETOE-2 Documentation," National Energy Software Center Note 83-84, August 25, 1983.

5. H. Henryson II, B. J. Toppel, and C. G. Stenberg, " $M C^{2}-2$ : A Code to Calculate Fast Neutron Spectra and Multi-group Cross Sections," ANL-8144, Argonne National Laboratory (1976).

6. W. M. Stacey, Jr., et al, "A New Space-Dependent Fast Neutron Multigroup Cross Section Preparation Capability," Trans. Am. Nucl. Soc., 15, 292 (1972).

7. R. D. Lawrence, "The DIF3D Nodal Neutronics Option for Two- and ThreeDimensional Diffusion Theory Calculations in Hexagonal Geometry," ANL-83-1, Argonne National Laboratory (1983).

8. C. H. Adams, "Specifications for VARI3D - A Multidimensional Reactor Design Sensitivity Code," FRA-TM-74, Argonne National Laboratory (1975).

9. W. S. Yang, Argonne National Laboratory, private correspondence, March 3, 1994

10. D. C. Wade and E. K. Fujita, "Trends versus Reactor Size of Passive Reactivity Shutdown and Control Performance," Nuclear Science and Engineering, 103, 182 (1989).

11. R. Ramamna and S. M. Lee, "The Thorium Cycle for Fast Breeder Reactors," Pramana Journal of Physics, 27, 129-137 (1986).

12. IAEA, "Thorium Fuel Cycle - Potential Benefits and Challenges," IAEA-TECDOC1450 (2005).

13. D. C. Crawford, D. L. Porter and S. L. Hayes, "Fuels for Sodium-Cooled Fast Reactors: US Perspective," Journal of Nuclear Materials, 371 (2007).

14. K. L. Basehore and N. E. Todreas, "SUPERENERGY-2: A Multiassembly SteadyState Computer Code for LMFBR Core Thermal-Hydraulic Analysis," PNL-3379 (1980).

15. R.G. Pahl et al. "Irradiation Behavior of Metallic Fast Reactor Fuels," Journal of Nuclear Materials, 188, 3-9 (1992).

16. F. Heidet and E. Greenspan, "Breed-and-Burn Depleted Uranium in Fast Reactors Without Actinides Separation," Proc. of Physor 2010, Pittsburgh, PA, May 9-14 (2010). 
17. F.Heidet and E. Greenspan, "Neutron Balance Analysis for Sustainability of Breedand-Burn Reactors," Nuclear Science and Engineering, 171, 13-31 (2012).

18. A. E. Waltar and A. B. Reynolds, "Fast Breeder Reactors," Pergamon Press (1981).

19. J. K. Fink, M.G. Chasanov and L. Leibowitz, "Thermophysical Properties of Thorium and Uranium Systems for Use in Reactor Safety Analysis," ANL-CEN-RSD-77-1, Argonne National Laboratory (1977).

20. C. E. Till, et al, "Fast Breeder Reactor Studies," ANL-80-40, Argonne National Laboratory (1980). 


\section{Appendix A. Sensitivity Study on Batch Number for Fuel Conversion with TRU Support}

The same approach as used in Section 3.2 is used for this sensitivity study. The reference AFR-100 core is operated for a given time and a fraction of the original uranium-based fuel is replaced with thorium-based fuel mixed with TRU. The required mass fraction of TRU required is determined for a 1,2, 4 and 10 batches mode of operation such as the fuel residence time is the same for all scenarios and the fuel discharge burnup at equilibrium is $\sim 100 \mathrm{GWd} / \mathrm{t}$. The $\mathrm{k}_{\text {eff }}$ evolutions at equilibrium are shown in Figure A.1 and the basic neutronics core performance characteristics at equilibrium are provided in Table A.1.

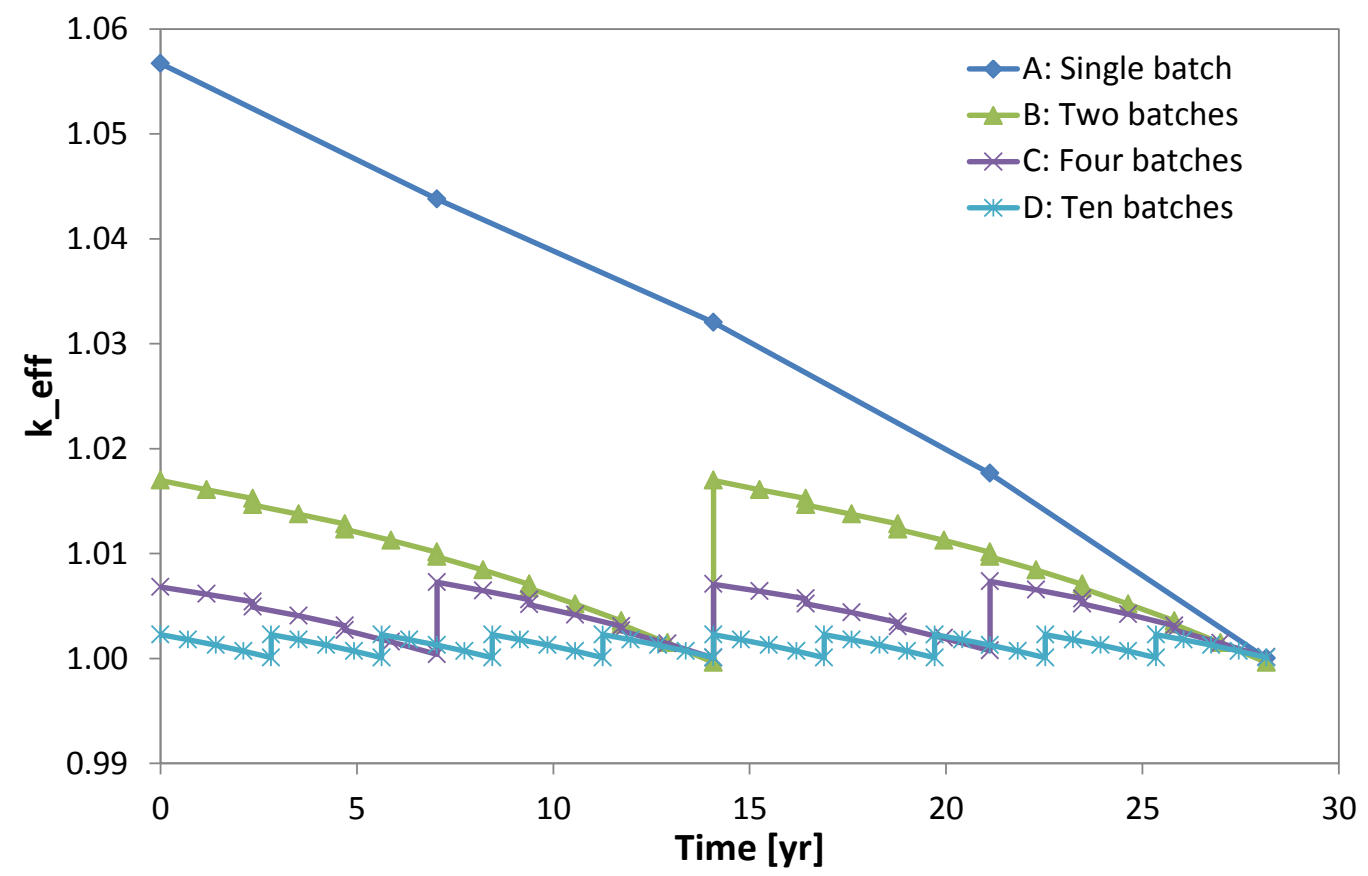

Figure A.1 $k_{\text {eff }}$ Evolution for Different Number of Batches with TRU Support

Table A.1 Basic Core Characteristics at Equilibrium

\begin{tabular}{|c|c|c|c|}
\hline Batch \# & Cycle length, $\mathrm{yr}$ & TRU mass fraction, $\%$ & Peak excess reactivity $\% \Delta \mathrm{k} / \mathrm{k}$ \\
\hline 1 & 28.2 & $20.3 \%$ & 5.7 \\
\hline 2 & 14.1 & $18.9 \%$ & 1.7 \\
\hline 4 & 7.0 & $18.6 \%$ & 0.8 \\
\hline 10 & 2.8 & $18.6 \%$ & 0.2 \\
\hline
\end{tabular}

When targeting a long cycle length without refueling thorium needs to be mixed with approximately $20.3 \%$ TRU (single batch mode). The resulting excess reactivity is $5.7 \%$ $\Delta \mathrm{k} / \mathrm{k}$ and a proper reactivity control system or a difference enrichment strategy will need to be designed in order to accommodate such a large excess reactivity. In comparison, 
using a 4-batch mode of operation the TRU mass fraction required is $18.6 \%$ and the excess reactivity is only $0.8 \% \Delta \mathrm{k}$, but the cycle length is decreased to about 7 years. 


\section{Appendix B. Whole Core Fuel Conversion Scenario Layouts with LEU Drivers and Thorium Blankets}

This approach is similar to the approach discussed in Section 3.3 in the fact that all the original uranium-based fuel assemblies are replaced at once with LEU fuel and thorium-based fuel. In this scenario the fuel assembly composition is homogeneous. There are 108 driver assemblies made of $20 \%$ LEU and 42 blanket assemblies made of pure ${ }^{232} \mathrm{Th}$. The relative radial power distributions of the four core layouts studied are shown at BOC in Figures B.1 to B.4. The blanket assemblies are the green assemblies, for which the relative radial power does not exceed 0.1 . The $\mathrm{k}_{\text {eff }}$ evolution for those four layouts is shown in Figure B.5.

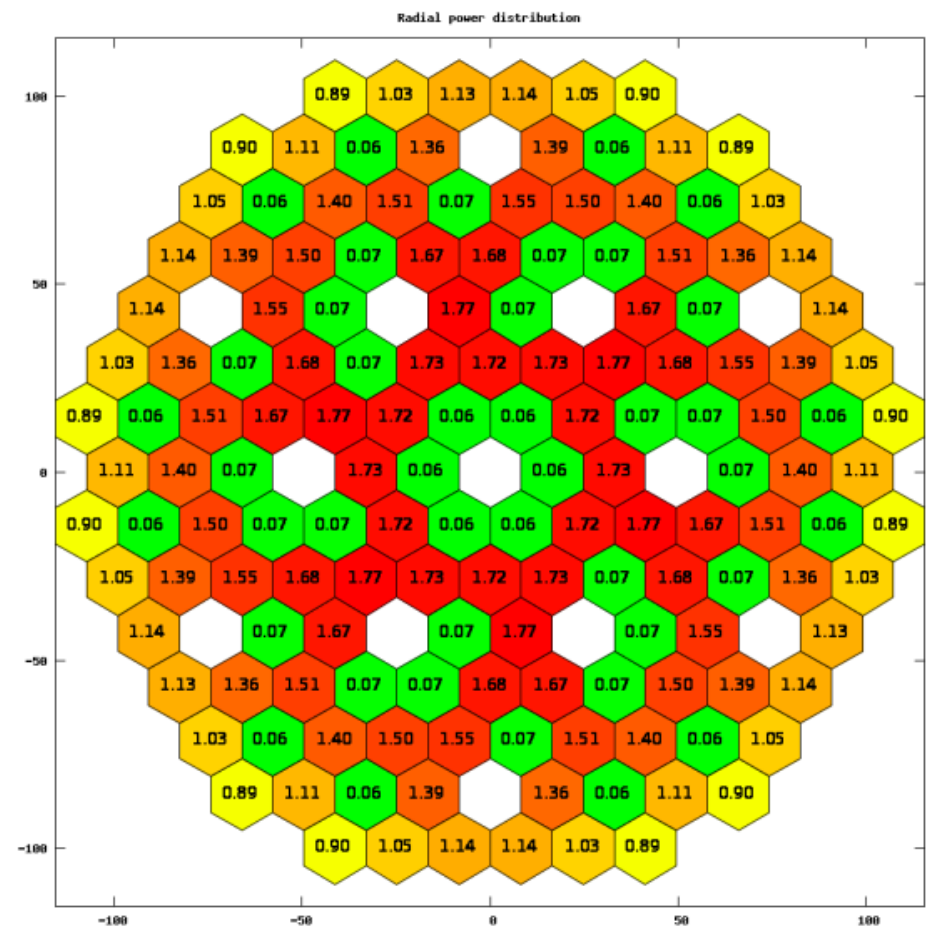

Figure B.1 Relative Radial Power Distribution for Layout A 


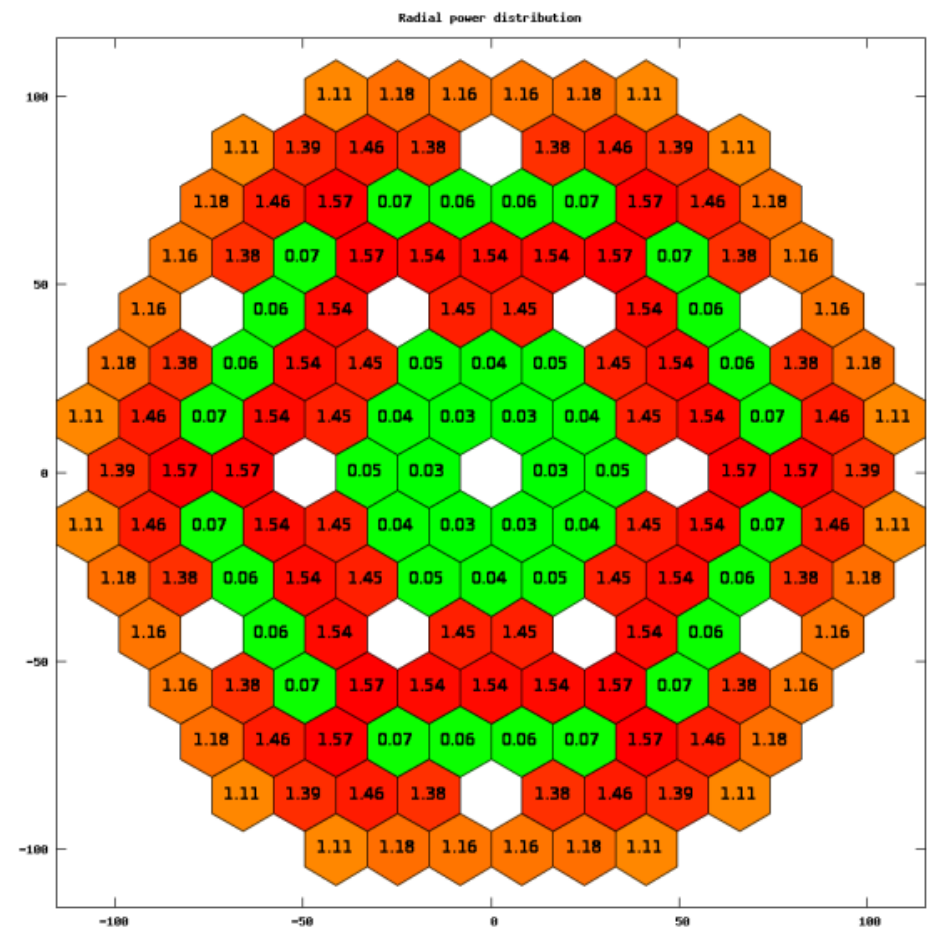

Figure B.2Relative Radial Power Distribution for Layout B

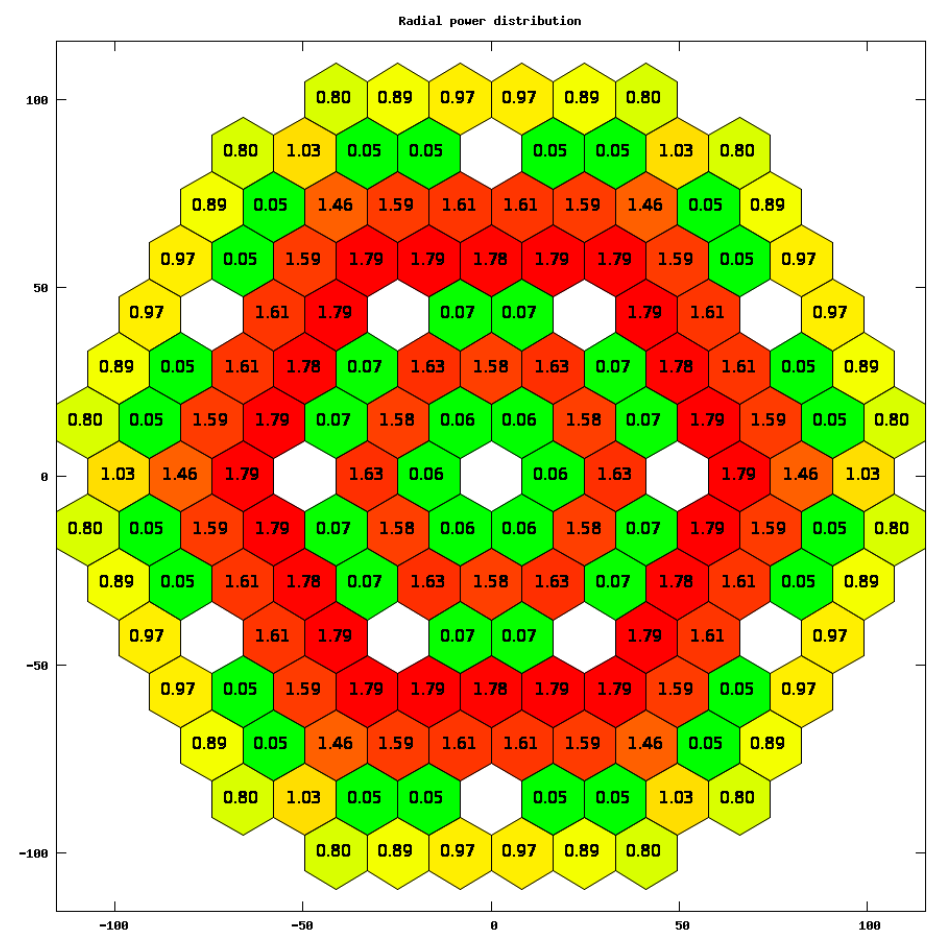

Figure B.3 Relative Radial Power Distribution for Layout C 


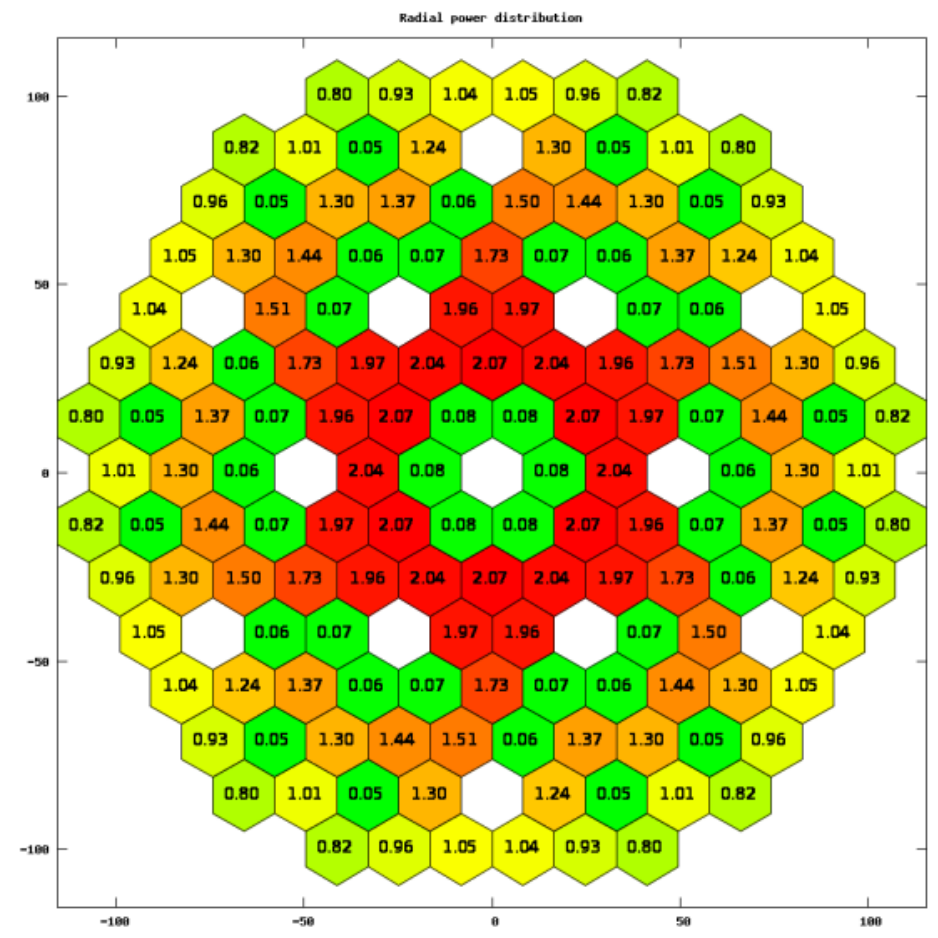

Figure B.4 Relative Radial Power Distribution for Layout D

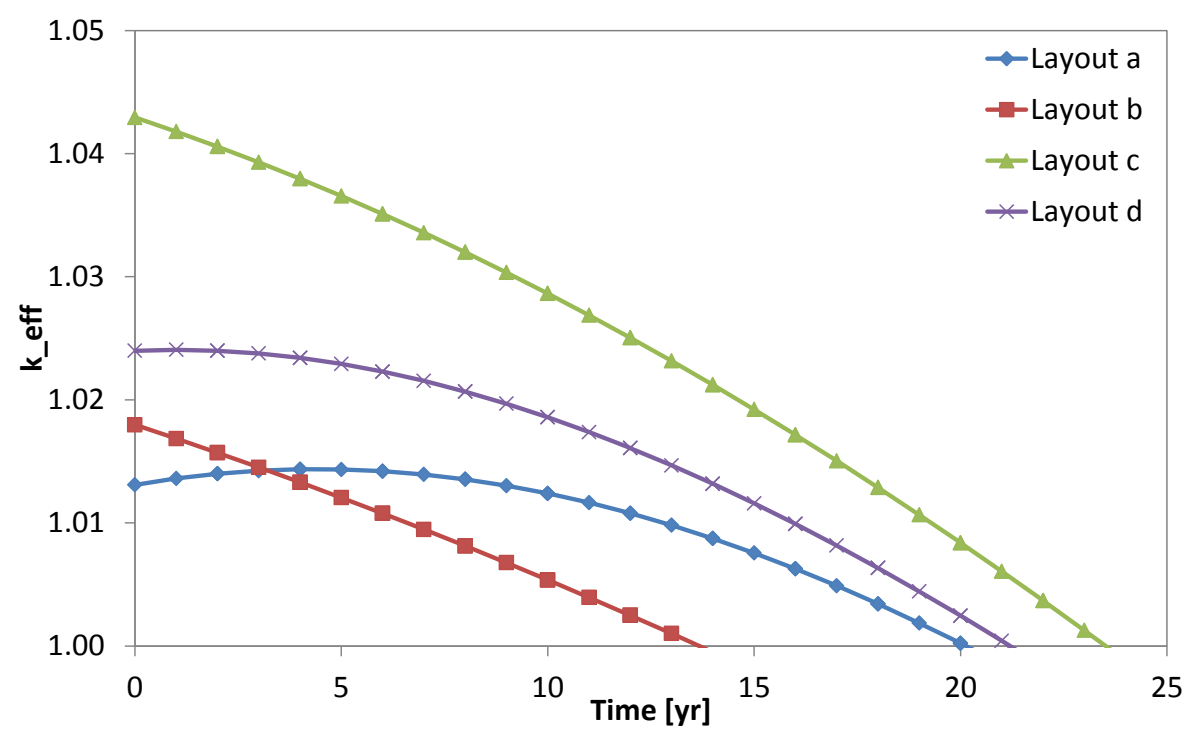

Figure B.5 $k_{\text {eff }}$ Evolution for the Four Core Layouts

The major issue with this approach is that the power generated in the blanket assemblies at EOC is up to 15 times larger than at BOC. In order to properly cool those assemblies it would be necessary to design an adaptive cooling system which would enable to modify the coolant flow rate in those assemblies during operation. When using the same flow rate at $\mathrm{BOC}$ and $\mathrm{EOC}$, the mean coolant outlet temperature of these 
assemblies will be low at BOC, reducing the overall plant thermal efficiency, or, the fuel and cladding temperatures will become too high at EOC. 